Article

\title{
Synthesis, Structure-Activity Relationships, and Antiviral Profiling of 1-Heteroaryl-2-Alkoxyphenyl Analogs as Inhibitors of SARS-CoV-2 Replication
}

Dorothée Bardiot ${ }^{1,+}$, Laura Vangeel ${ }^{2,+}$, Mohamed Koukni ${ }^{1}$, Philippe Arzel ${ }^{1}$, Marleen Zwaagstra ${ }^{3}$, Heyrhyoung Lyoo ${ }^{3}$, Patrick Wanningen ${ }^{4}{ }^{D}$, Shamshad Ahmad ${ }^{5}$, Linlin Zhang ${ }^{6}$, Xinyuanyuan Sun ${ }^{6} \mathbb{D}_{\text {, }}$ Adrien Delpal ${ }^{7}$, Cecilia Eydoux ${ }^{7}$, Jean-Claude Guillemot ${ }^{7}$, Eveline Lescrinier ${ }^{8} \mathbb{D}$, Hugo Klaassen ${ }^{1}$, Pieter Leyssen ${ }^{2}$, Dirk Jochmans ${ }^{2}\left(\mathbb{D}\right.$, Karolien Castermans ${ }^{1}$, Rolf Hilgenfeld ${ }^{6,9} \mathbb{D}$, Colin Robinson ${ }^{5}$, Etienne Decroly $^{7}{ }^{\mathbb{D}}$, Bruno Canard ${ }^{7}$, Eric J. Snijder ${ }^{4}{ }^{(D}$, Martijn J. van Hemert ${ }^{4}$, Frank van Kuppeveld ${ }^{3}$, Patrick Chaltin ${ }^{1,10}$, Johan Neyts ${ }^{2}\left(\mathbb{D}\right.$, Steven De Jonghe ${ }^{2, *}$ and Arnaud Marchand $1, * \mathbb{D}$

check for updates

Citation: Bardiot, D.; Vangeel, L.; Koukni, M.; Arzel, P.; Zwaagstra, M.; Lyoo, H.; Wanningen, P.; Ahmad, S.;

Zhang, L.; Sun, X.; et al. Synthesis,

Structure-Activity Relationships, and Antiviral Profiling of

1-Heteroaryl-2-Alkoxyphenyl

Analogs as Inhibitors of SARS-CoV-2

Replication. Molecules 2022, 27, 1052.

https://doi.org/10.3390/

molecules27031052

Academic Editors: Libor Grubhoffer, Masanori Baba and Roberta Costi

Received: 20 December 2021

Accepted: 24 January 2022

Published: 4 February 2022

Publisher's Note: MDPI stays neutral with regard to jurisdictional claims in published maps and institutional affiliations.

Copyright: (C) 2022 by the authors. Licensee MDPI, Basel, Switzerland. This article is an open access article distributed under the terms and conditions of the Creative Commons Attribution (CC BY) license (https:// creativecommons.org/licenses/by/ $4.0 /)$.
1 Centre for Innovation and Stimulation of Drug Discovery (CISTIM), Gaston Geenslaan 2, 3001 Leuven, Belgium; dorothee.bardiot@cistim.be (D.B.); mohamed.koukni@cistim.be (M.K.); philippe.arzel@cistim.be (P.A.); hugo.klaassen@cistim.be (H.K.); karolien.castermans@cistim.be (K.C.); patrick.chaltin@kuleuven.be (P.C.)

2 Laboratory of Virology and Chemotherapy, KU Leuven, Department of Microbiology, Immunology and Transplantation, Rega Institute for Medical Research, Herestraat 49, 3000 Leuven, Belgium; laura.vangeel@kuleuven.be (L.V.); pieter.Leyssen@kuleuven.be (P.L.); dirk.jochmans@kuleuven.be (D.J.); johan.neyts@kuleuven.be (J.N.)

3 Virology Section, Infectious Disease and Immunology Division, Department of Biomolecular Health Sciences, Faculty of Veterinary Medicine, Utrecht University, 3584 CL Utrecht, The Netherlands; m.zwaagstra@uu.nl (M.Z.); h.r.lyoo@uu.nl (H.L.); f.j.m.vankuppeveld@uu.nl (F.v.K.)

4 Department of Medical Microbiology, Leiden University Medical Center, 2300 RC Leiden, The Netherlands; p.wanningen@lumc.nl (P.W.); e.j.snijder@lumc.nl (E.J.S.); m.j.van_hemert@lumc.nl (M.J.v.H.)

5 Drug Discovery Unit, School of Life Sciences, University of Dundee, Dundee DDI 5EH, UK; s.a.ahmad@dundee.ac.uk (S.A.); c.x.robinson@dundee.ac.uk (C.R.)

6 Institute of Molecular Medicine, University of Lübeck, 23562 Lübeck, Germany; llzhang@biochem.uni-luebeck.de (L.Z.); xinyuanyuan.sun@uni-luebeck.de (X.S.); rolf.hilgenfeld@uni-luebeck.de (R.H.)

7 Laboratory Architecture et Fonction des Macromolécules Biologiques (AFMB), UMR 7257, Centre National de la Recherche Scientifique (CNRS), Aix Marseille University, CEDEX 9, 13288 Marseille, France; adrien.delpal@univ-amu.fr (A.D.); cecilia.eydoux@univ-amu.fr (C.E.); jean-claude.guillemot@univ-amu.fr (J.-C.G.); etienne.decroly@univ-amu.fr (E.D.); bruno.canard@univ-amu.fr (B.C.)

8 Medicinal Chemistry, Rega Institute for Medical Research, KU Leuven, Herestraat 49, 3000 Leuven, Belgium; eveline.lescrinier@kuleuven.be

9 German Center for Infection Research (DZIF), Hamburg-Lübeck-Borstel-Riems Site, University of Lübeck, 23562 Lübeck, Germany

10 Center for Drug Design and Development (CD3), KU Leuven R\&D, Waaistraat 6, 3000 Leuven, Belgium

* Correspondence: steven.dejonghe@kuleuven.be (S.D.J.); arnaud.marchand@cistim.be (A.M.)

+ These authors contributed equally to this work.

Abstract: The severe acute respiratory syndrome coronavirus 2 (SARS-CoV-2), the causative agent of COVID-19, has led to a pandemic, that continues to be a huge public health burden. Despite the availability of vaccines, there is still a need for small-molecule antiviral drugs. In an effort to identify novel and drug-like hit matter that can be used for subsequent hit-to-lead optimization campaigns, we conducted a high-throughput screening of a $160 \mathrm{~K}$ compound library against SARS-CoV-2, yielding a 1-heteroaryl-2-alkoxyphenyl analog as a promising hit. Antiviral profiling revealed this compound was active against various beta-coronaviruses and preliminary mode-of-action experiments demonstrated that it interfered with viral entry. A systematic structure-activity relationship (SAR) study demonstrated that a 3- or 4-pyridyl moiety on the oxadiazole moiety is optimal, whereas the oxadiazole can be replaced by various other heteroaromatic cycles. In addition, the alkoxy group tolerates some structural diversity. 
Keywords: COVID-19; SARS-CoV-2; 1,2,4-oxadiazole; 1-heteroaryl-2-alkoxyphenyl analogs

\section{Introduction}

The severe acute respiratory syndrome coronavirus 2 (SARS-CoV-2) is the causative agent of the human coronavirus disease 2019 (COVID-19). SARS-CoV-2 is a newly discovered coronavirus that was first identified in December 2019 in Wuhan, China, and spread quickly throughout the world, infecting and causing death to millions of people [1,2]. On 11 March 2020, the World Health Organization (WHO) officially declared COVID-19 a global pandemic. As of October 2021, more than 235 million people were infected with SARS-CoV-2 and almost 5 million people have died due to COVID-19 [3].

Major research efforts were carried out to control this pandemic. Using a number of different technology platforms (such as messenger RNA and vector-based vaccines), the development of various vaccines moved forward at an unparalleled speed and several of them received marketing approval [4]. Despite the success of these SARS-CoV-2 vaccines, there is still an urgent need for small molecule therapeutics. As a drug discovery program aiming at the development of SARS-CoV-2-specific antiviral drugs from scratch would take a long time, the initial focus has been on the repurposing of known drugs and drug candidates. Several large-scale phenotypic screening campaigns of different repurposing compound libraries have been described in the literature. With different SARS-CoV-2infected cell lines and different readouts being used, the outcome has been heterogeneous and a wide variety of compounds has been discovered [5-8].

Drug discovery programs focusing on viral proteins that are essential for SARS-CoV-2 replication are also being pursued. The viral genome of SARS-CoV-2 encodes for 16 nonstructural proteins (nsp1-nsp16). These are highly conserved among various coronaviruses and many of them are excellent candidates as targets for the discovery of antiviral agents [9]. Examples include the cap guanine N7-methyltransferase and $3^{\prime}-5^{\prime}$ exonuclease activity of nsp14 [10], the nsp15 endoribonuclease [11], and the papain-like protease (PLpro) activity of nsp3 [12]. Targets that are most intensively studied are nsp5, also known as the chymotrypsin-like protease (3CLpro) or the viral main protease (Mpro) [13] and the RNAdependent RNA polymerase (RdRp, encoded by nsp12) [14,15]. Drug discovery programs on the latter two enzymes have afforded drugs and drug candidates for the treatment of SARS-CoV-2 viral infections. PF-00835231 is a potent SARS-CoV-2 Mpro inhibitor, when evaluated in a biochemical assay and shows potent SARS-CoV-2 antiviral activity in a cellbased antiviral assay. Its corresponding phosphate prodrug, also known as PF-07304814, is currently undergoing clinical trials for COVID-19 treatment, after intravenous administration [16]. More recently, Pfizer disclosed PF-07321332, an orally bioavailable SARS-CoV-2 Mpro inhibitor, displaying excellent in vitro potency in biochemical and cell-based antiviral assays. Moreover, it is endowed with good activity in SARS-CoV-2 mouse and hamster models, after oral administration [17]. Pfizer recently reported interim data of a phase II/III clinical trial (unpublished data) demonstrating a marked reduction in progression to severe COVID-19 or hospitalization if treatment in high-risk patients is initiated during the first 5 days of onset of symptoms.

The viral RNA-dependent RNA polymerase (RdRp) is another attractive target for the treatment of COVID-19 patients. Remdesivir is a phosphoramidate prodrug of the C-nucleoside GS-441524 that received FDA approval for the treatment of adult and pediatric (aged > 12 years) SARS-CoV-2-infected patients. Since it requires intravenous administration, remdesivir usage is limited to hospital settings [18]. Yet, Gilead reported (unpublished) that early intravenous treatment of at risk-patients markedly reduced progression to severe COVID-19. Molnupiravir, an ester prodrug of $N$-4-hydroxycytidine, is orally bioavailable and has shown promising activity in various SARS-CoV-2 preclinical animal models [19] and was licensed for medical use in the United Kingdom and the EU for use in patients 
suffering from mild to moderate COVID-19 and who have at least one risk factor for developing severe illness.

Cell-based phenotypic based screening campaigns of structurally diverse, drug-like compound libraries are another important method to discover novel antiviral hit compounds which serve as a basis for further development. Advantages of this approach are that such screens are physiologically more relevant than target-based screens and that there is a priori no bias towards a particular target and hence allows to select antiviral agents targeting different viral, as well as cellular, factors [20]. To the best of our knowledge, this type of screening for the discovery of novel hit matter against SARS-CoV-2 has not been described in the literature. In this manuscript, the discovery of a novel SARS-CoV-2 hit compound, its preliminary structure-activity relationship (SAR) study, and its antiviral profile are discussed.

\section{Results}

\subsection{Hit Identification}

In order to identify potential hits, the CD3 (Centre for Drug Design and Discovery, KU Leuven) small molecule library was screened against SARS-CoV-2 in VeroE6 cells, which constitutively expresses the enhanced green fluorescent protein (eGFP) [21]. A reduced eGFP expression correlates with the cytopathogenic effect (CPE) of SARS-CoV-2 and, hence, the measurement of the fluorescence by high-content imaging can be used as an indication for the antiviral potency. In the presence of a non-toxic antivirally active agent, the cytopathogenicity is inhibited and the fluorescent signal is maintained. In the first round of screening, compounds were tested at a single concentration of $10 \mu \mathrm{M}$ in a 384-well plate format. Initial hits were followed up by full-dose response analysis allowing to express the antiviral activity as the concentration producing $50 \%$ antiviral effect $\left(\mathrm{EC}_{50}\right)$. In parallel, the cellular toxicity of the compounds, which was expressed as the $50 \%$ cytotoxic concentration $\left(\mathrm{CC}_{50}\right)$, was determined using mock-infected VeroE6 cells. Among the various hits, 5(2-((1-phenethylpyrrolidin-3-yl)oxy)phenyl)-3-(pyridin-4-yl)-1,2,4-oxadiazole 1 (Figure 1) displayed an $\mathrm{EC}_{50}$ value of $4.7 \mu \mathrm{M}$ and a $\mathrm{CC}_{50}$ value of $21 \mu \mathrm{M}$, and was considered a promising starting point for further chemistry.

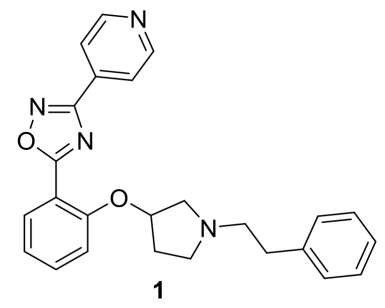

Figure 1. Structure of hit compound 1.

\subsection{Chemistry}

Compound 1 and analogs with various alkoxy substituents on the phenyl ring were prepared following one of the three synthetic routes as shown in Scheme 1. In a first step, the key intermediate 1,2,4-oxadiazole 4 was synthesized by condensation under microwave irradiation [22] of the benzaldehyde 2 and the $\mathrm{N}^{\prime}$-hydroxy-isonicotinamidine 3. Several methods were used to introduce the alkoxy substituents. Mitsunobu reactions with the corresponding 3-hydroxypyrrolidine analog using 1,1'-(azodicarbonyl)dipiperidine (ADDP) [23] and tributylphosphine provided the desired compounds $\mathbf{1}$ and $\mathbf{8}$ in one step. To introduce the desired substituents ( $\mathrm{R}^{1}$ group) on the cyclic amine at the final step, an alternative three-step sequence was developed. A Mitsunobu reaction with commercially available alcohols bearing a Boc-protected cyclic amine afforded intermediates 5 , which were deprotected in acidic conditions to release the free amines 6 , which were subsequently alkylated with various alkyl or cycloalkyl halides, affording target compounds 9-12. Alternatively, alkylation of 4 with dibromoethane, followed by bromine displacement with 
cyclopentylamines, allowed to prepare compounds 13 and 14 with an ethyleneoxy linker between the phenyl and the amine moiety.

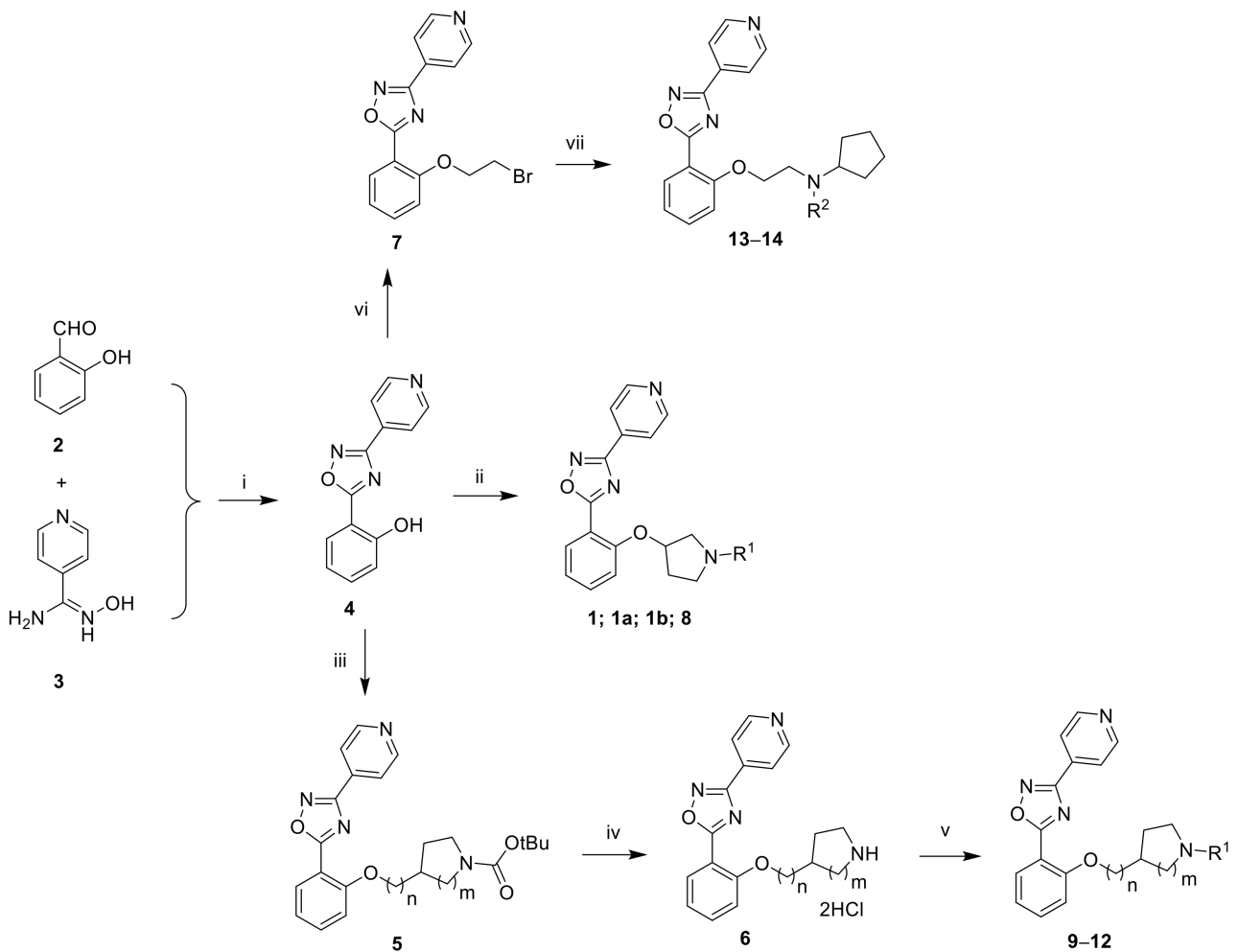

Scheme 1. Synthetic routes to compound 1 and analogs with modification of the alkoxy substituent. Reagents and conditions: (i) EtOH, MW irradiation, $160{ }^{\circ} \mathrm{C}, 1 \mathrm{~h}, 26 \%$; (ii) $\mathrm{nBu}_{3} \mathrm{P}$, ADDP, alcohol, $\mathrm{THF}$, rt, 2 d, 51\%; (iii) $\mathrm{PPh}_{3}$, DIAD, alcohol, THF, rt, overnight, 95-99\%; (iv) $4 \mathrm{~N} \mathrm{HCl}$ in dioxane, dioxane, rt, 4 to $16 \mathrm{~h}, 100 \%$; (v) $\mathrm{R}^{1}-\mathrm{X}, \mathrm{K}_{2} \mathrm{CO}_{3}, \mathrm{DMF}, 80{ }^{\circ} \mathrm{C}, 2 \mathrm{~h}, 26-40 \%$; (vi) dibromoethane, $\mathrm{K}_{2} \mathrm{CO}_{3}, \mathrm{DMF}, 80{ }^{\circ} \mathrm{C}$, $2 \mathrm{~h}, 46 \%$; (vii) amine, $\mathrm{K}_{2} \mathrm{CO}_{3}, \mathrm{DMF}, 80^{\circ} \mathrm{C}, 2 \mathrm{~h}, 20 \%$.

In order to access a small library of compounds bearing various groups on the oxadiazole, a convergent route was designed to generate several compounds in one step from a common intermediate (Scheme 2). Briefly, the key building block 19 was prepared in three steps from phenol 15 and $N$-Boc-hydroxy-pyrrolidine 16 by Mitsunobu reaction, followed by Boc deprotection and $N$-alkylation by reductive amination with cyclopentanone. The ester 19 or the lithium salt of the corresponding carboxylic acid 20 were then converted into the desired oxadiazoles $\mathbf{2 3}-\mathbf{3 1}$ by condensation with various amidoximes 22 , which were either commercially available or prepared by nucleophilic attack of hydroxylamine on appropriate nitriles $\mathbf{2 1 .}$

In order to study the importance of the 1,2,4-oxadiazole ring for antiviral activity, several synthetic routes were developed to obtain analogs bearing other 5-membered heteroaryls (Schemes 3-6). The synthesis of an analog having an isomeric 1,2,4-oxadiazole ring is shown in Scheme 3. The required amidoxime 34 was synthesized in three steps from intermediate 19. Treatment of the ester with aqueous ammonia yielded the primary amide 32. Dehydration with propylphosphonic anhydride (T3P) [24], followed by treatment with hydroxylamine yielded amidoxime 34. Oxadiazole ring formation via an O-acylamidoxime intermediate using EDC/HOBt as coupling agents provided the desired compound 35.

The reaction of carboxylic acid 36 with isonicotinohydrazide 37 using phosphorus oxychloride as a dehydrating agent provided compound 38 with a 1,3,4-oxadiazole ring (Scheme 4).

To access compound 46, the 1,2,4-thiadiazole ring was not synthesized since thiadiazole 39 is a commercially available building block (Scheme 5) [25]. A first selective 
Suzuki-Miyaura coupling using ortho-methoxyphenylboronic acid occurred on the chlorine and was followed by a second coupling with pyridin-4-ylboronic acid furnishing intermediate 42. Demethylation with $\mathrm{LiBr}$ led to the formation of the phenol 43, which underwent a Mitsunobu reaction with $N$-Boc-3-hydroxypyrrolidine to provide intermediate 44. Removal of the Boc protecting group under acidic conditions, followed by alkylation of the pyrrolidine moiety by reductive amination, furnished the desired compound 46 .

The isoxazole analog 49 was obtained via a cyclization of oxime 47 with ester 19 in the presence of LDA, followed by treatment with $12 \mathrm{~N} \mathrm{HCl}$ at $70^{\circ} \mathrm{C}$.

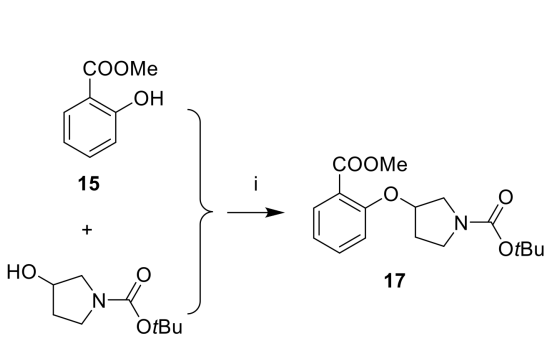

16
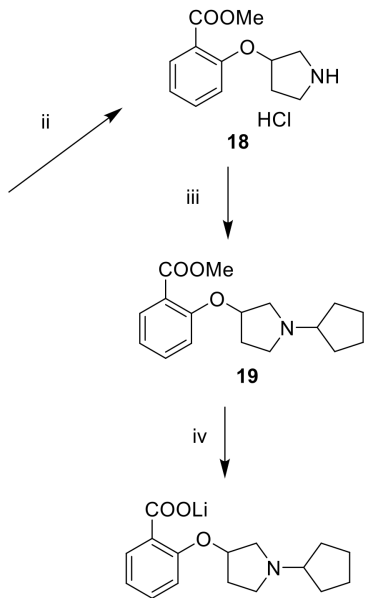
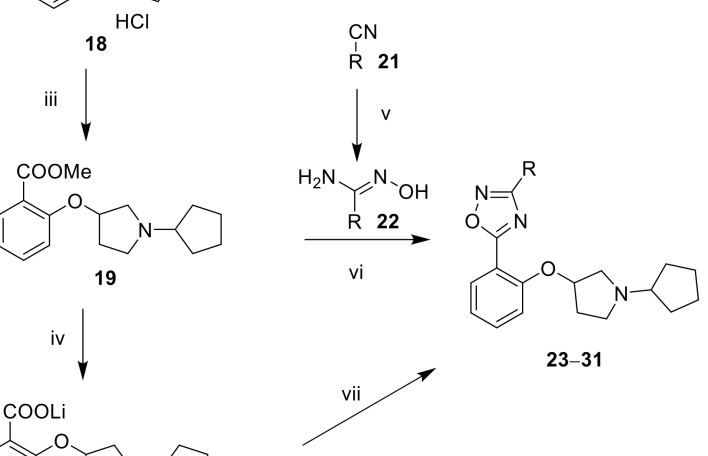

Scheme 2. Synthetic route to compounds with various substituents on the oxadiazole. Reagents and conditions: (i) $\mathrm{PPh}_{3}$, DIAD, THF, rt, overnight, 33\%; (ii) $4 \mathrm{~N} \mathrm{HCl}$ in dioxane, dioxane, rt, overnight, $100 \%$; (iii) cyclopentanone, $\mathrm{NaBH}(\mathrm{OAc})_{3}, \mathrm{CH}_{2} \mathrm{Cl}_{2}$, rt, overnight, 77\%; (iv) $\mathrm{LiOH}, \mathrm{THF}, \mathrm{MeOH}, \mathrm{H}_{2} \mathrm{O}$, $60{ }^{\circ} \mathrm{C}, 6 \mathrm{~h}, 82 \%$; (v) $\mathrm{NH}_{2} \mathrm{OH} . \mathrm{HCl}, \mathrm{K}_{2} \mathrm{CO}_{3}, \mathrm{EtOH}, 80^{\circ} \mathrm{C}$, overnight; (vi) 22, $\mathrm{NaOH}$, DMSO, rt, overnight, $4 \%$; (vii) (a) 22, HATU, DIPEA, DMF, rt, 6 h; (b) $100{ }^{\circ} \mathrm{C}$, overnight, $15 \%$.

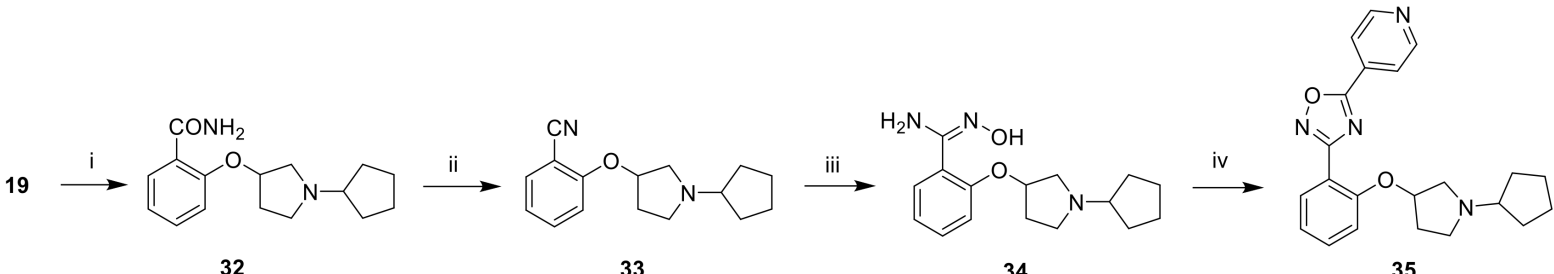

Scheme 3. Synthetic route to compound 35 with an isomeric 1,2,4-oxadiazole ring. Reagents and conditions: (i) $\mathrm{NH}_{4} \mathrm{OH}$, dioxane, $100{ }^{\circ} \mathrm{C}$, overnight; (ii) T3P, EtOAc, $60{ }^{\circ} \mathrm{C}$, overnight, $54 \%$ over 2 steps; (iii) $\mathrm{NH}_{2} \mathrm{OH} . \mathrm{HCl}, \mathrm{DIPEA}, \mathrm{EtOH}, 70^{\circ} \mathrm{C}$, overnight, crude; (iv) (a) isonicotinic acid, EDC.HCl, HOBt, DIPEA, DMF, rt, 6 h; (b) $80^{\circ} \mathrm{C}$, overnight, $9 \%$.

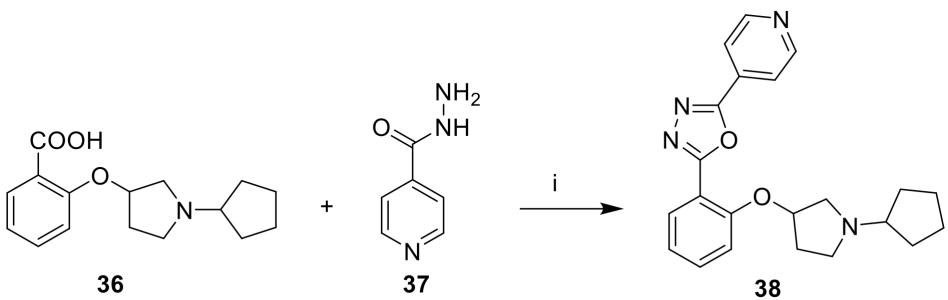

Scheme 4. Synthetic route to compound 38 with a 1,3,4-oxadiazole ring. Reagents and conditions: (i) $\mathrm{POCl}_{3}, 90{ }^{\circ} \mathrm{C}$, overnight, $19 \%$. 

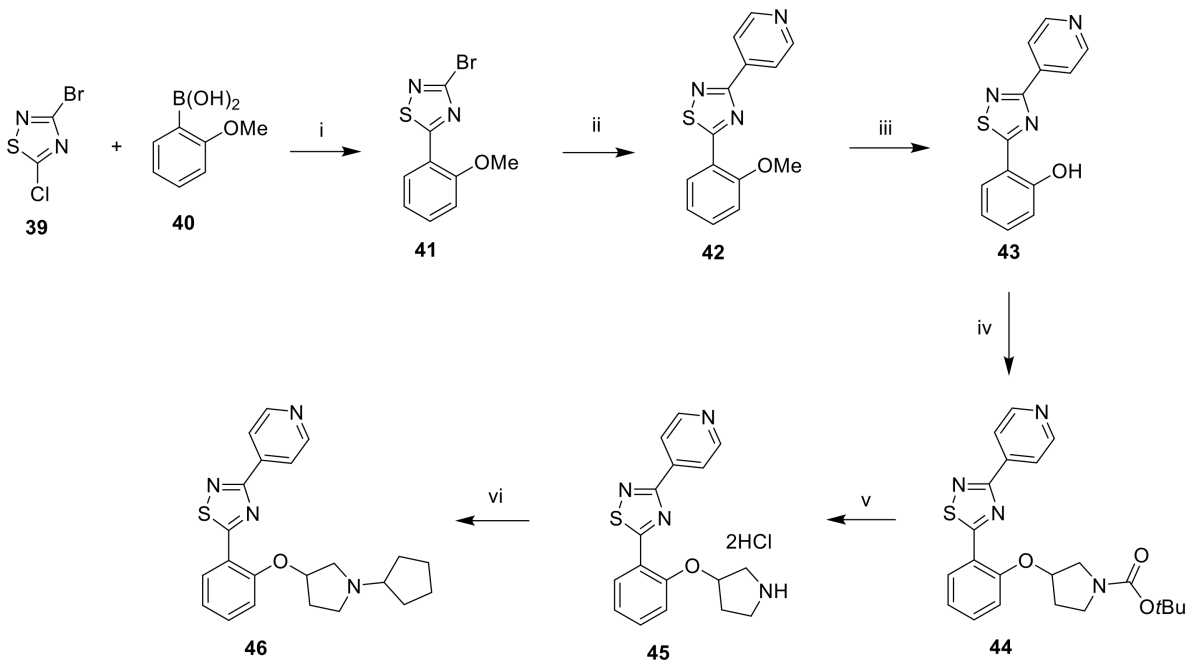

Scheme 5. Synthetic route to compound 46 with a 1,2,4-thiadiazole ring. Reagents and conditions: (i) $\mathrm{PdCl}_{2}$ (dppf), $\mathrm{CsF}$, dioxane, $\mathrm{H}_{2} \mathrm{O}, 85^{\circ} \mathrm{C}$, overnight, $46 \%$; (ii) pyridin-4-ylboronic acid, $\mathrm{PdCl}_{2}$ (dppf), $\mathrm{K}_{2} \mathrm{CO}_{3}$, dioxane, $\mathrm{H}_{2} \mathrm{O}, 85^{\circ} \mathrm{C}$, overnight, $83 \%$; (iii) $\mathrm{LiBr}$, pTsOH, $\mathrm{NMP}, 150{ }^{\circ} \mathrm{C}, 1.5 \mathrm{~h}, 54 \%$; (iv) $\mathrm{PPh}_{3}$, DIAD, tert-butyl 3-hydroxypyrrolidine-1-carboxylate, THF, rt, overnight, 35\%; (v) $4 \mathrm{~N} \mathrm{HCl}$ in dioxane, dioxane, rt, 2 h, 100\%; (vi) cyclopentanone, $\mathrm{NaBH}(\mathrm{OAc})_{3}, \mathrm{MeOH}, \mathrm{CH}_{2} \mathrm{Cl}_{2}$, rt, overnight, 9\%.

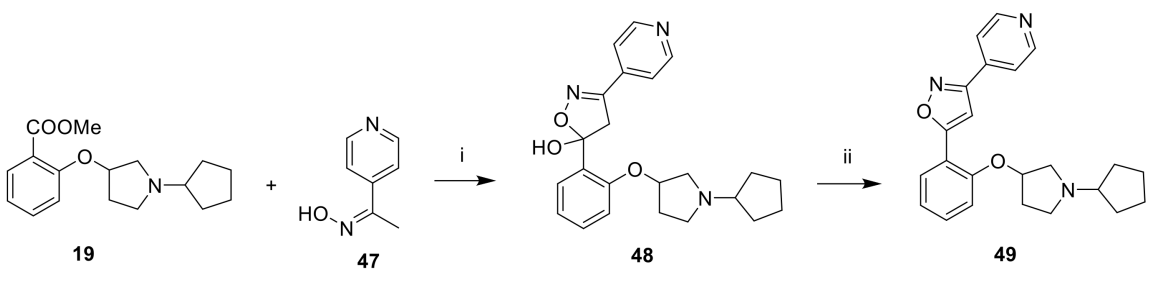

Scheme 6. Synthetic route to compound 49 with an isoxazole ring. Reagents and conditions: (i) $2 \mathrm{M}$ LDA in THF, $-78^{\circ} \mathrm{C}, 2.5 \mathrm{~h}$, crude; (ii) $12 \mathrm{~N} \mathrm{HCl}, \mathrm{MeOH}, 70{ }^{\circ} \mathrm{C}, 3 \mathrm{~h}, 12 \%$.

\subsection{Biological Evaluation}

\subsubsection{Early SAR Investigation}

All compounds were evaluated for anti-SARS-CoV-2 activity in VeroE6 cells, which allowed to establish first SAR trends. As these cells have a high expression of the efflux transporter P-glycoprotein (P-gp), the assays were performed in the presence of CP-100356, a well-known P-gp inhibitor [12]. In all experiments, GS-441524 (the parent nucleoside of remdesivir) [26] was included as a positive control, with an average $\mathrm{EC}_{50}$ and $\mathrm{CC}_{50}$ value of $0.82 \mu \mathrm{M}$ and $72.9 \mu \mathrm{M}$, respectively.

As compound $\mathbf{1}$ presents a chiral center, the two enantiomers $\mathbf{1 a}$ and $\mathbf{1 b}$ were synthesized using optically pure pyrrolidine building blocks and tested against SARS-CoV-2. The three compounds $\mathbf{1}, \mathbf{1 a}$, and $\mathbf{1 b}$ showed similar biological profiles, indicating a limited influence of the stereochemistry on the antiviral activity (Table 1). All the other compounds were then synthesized and evaluated as racemic mixtures.

Table 1. Antiviral activity and cytotoxicity of racemic $\mathbf{1}$ and its enantiomers $\mathbf{1 a}$ and $\mathbf{1 b}$.

\begin{tabular}{ccccc}
\hline Compound & & $\begin{array}{c}\text { SARS-CoV-2 } \\
\mathbf{E C}_{\mathbf{5 0}}(\boldsymbol{\mu M})\end{array}$ & $\begin{array}{c}\text { MTS } \\
\mathbf{C C}_{\mathbf{5 0}}(\boldsymbol{\mu M})\end{array}$ & $\begin{array}{c}\text { SI } \\
\left(\mathbf{C C}_{\mathbf{5 0}} / \mathbf{E C}_{\mathbf{5 0}}\right)\end{array}$ \\
\hline $\mathbf{1}$ & Racemic & $4.7 \pm 3.0$ & $21 \pm 11$ & 4.5 \\
$\mathbf{1 a}$ & $(R)$-enantiomer & $3.6 \pm 1.8$ & $29 \pm 24$ & 8.1 \\
$\mathbf{1 b}$ & (S)-enantiomer & $1.4 \pm 0.1$ & $18 \pm 11$ & 12.8 \\
\hline
\end{tabular}


The SAR was explored around three distinct structural subunits of hit compound 1: The alkoxy group on the phenyl moiety, the substituent on the oxadiazole ring, and the oxadiazole ring itself. We first investigated the alkoxy group modifications (Table 2), taking into account that an amino group was required for antiviral activity (data not shown). Several structural modifications around this alkoxy group were well tolerated: Replacement of the phenethyl substituent on the pyrrolidine of hit compound $\mathbf{1}$ by a cyclopentyl (compound 8) or a methylcyclopentyl (compound 9) moiety, the insertion of an additional methylene linker between the oxygen and the pyrrolidine (compound 10) or replacement of the pyrrolidine by a piperidine (compound 12). A cyclic amine was not essential for the antiviral potency as shown by compounds 13 and 14 with a linear secondary or tertiary amine. On the other hand, the introduction of a methylene group between the pyrrolidine and the phenoxy ring of compound 10 yielded analog 11, which was 20-fold less active than compound $\mathbf{1 0 .}$

Table 2. Antiviral activity and cytotoxicity of compounds 1, 8-14.

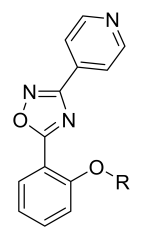

\begin{tabular}{|c|c|c|c|c|}
\hline Compound & $\mathbf{R}$ & $\begin{array}{c}\text { SARS-CoV-2 } \\
\text { EC }_{50}(\mu \mathrm{M})\end{array}$ & $\begin{array}{c}\text { MTS } \\
\mathrm{CC}_{50}(\mu \mathrm{M})\end{array}$ & $\begin{array}{c}\mathrm{SI} \\
\left(\mathrm{CC}_{50} / \mathrm{EC}_{50}\right)\end{array}$ \\
\hline 1 & & $4.7 \pm 3.0$ & $21 \pm 11$ & 4.5 \\
\hline 8 & & $5.4 \pm 3.5$ & $41 \pm 25$ & 7.6 \\
\hline 9 & & $1.6 \pm 0.8$ & $24 \pm 8$ & 15 \\
\hline 10 & & $1.7 \pm 0.3$ & $27 \pm 6$ & 15.9 \\
\hline 11 & & $40 \pm 14$ & $>50$ & 1.3 \\
\hline 12 & & $1.7 \pm 0.5$ & $46 \pm 18$ & 27.1 \\
\hline 13 & & $8.4 \pm 2.5$ & $46 \pm 13$ & 5.5 \\
\hline 14 & & $8.5 \pm 4.0$ & $37 \pm 11$ & 4.4 \\
\hline
\end{tabular}

We next investigated modifications around the 1,2,4-oxadiazole subunit (Table 3). To probe the effect of substituents on the 1,2,4-oxadiazole moiety on the antiviral activity, a number of derivatives were synthesized (compounds 23-31). Albeit the 3-pyridinyl analog 23 was equipotent to 8 , the introduction of a second nitrogen into the ring led to potency loss (3-fold for the pyrimidine $\mathbf{2 4}$ and more than 10-fold for the pyridazine 25). The phenyl analog 26 showed only cytotoxicity. Since the 3- or 4-pyridyl derivatives seemed to be the optimal 6-membered ring, the addition of substituents was explored. Several groups with various sizes and electronic properties were well tolerated at different positions of the 3-pyridyl moiety, such as a methoxy (compound 27), a trifluoromethyl (compounds 28-29), or a methyl group (compound 30). The positive effect of the methyl group in ortho position to the oxadiazole was confirmed also with the 4-pyridyl analog 31. 
Table 3. Antiviral activity and cytotoxicity of compounds 8 and 23-31.

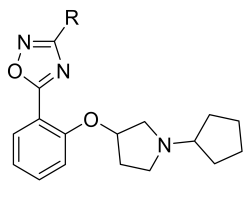

\begin{tabular}{|c|c|c|c|c|}
\hline Compound & $\mathbf{R}$ & $\begin{array}{c}\text { SARS-CoV-2 } \\
\text { EC }_{50}(\mu \mathrm{M})\end{array}$ & $\begin{array}{c}\text { MTS } \\
\mathrm{CC}_{50}(\mu \mathrm{M}) \\
\end{array}$ & $\begin{array}{c}\mathrm{SI} \\
\left(\mathrm{CC}_{50} / \mathrm{EC}_{50}\right) \\
\end{array}$ \\
\hline 8 & & $5.4 \pm 3.5$ & $41 \pm 25$ & 7.6 \\
\hline 23 & & $8.4 \pm 5.7$ & $>50$ & $>6$ \\
\hline 24 & & $15 \pm 2$ & $>50$ & $>3.3$ \\
\hline 25 & & $>50$ & $>50$ & 1 \\
\hline 26 & & $>50$ & $9.0 \pm 2.5$ & $<1$ \\
\hline 27 & & $4.1 \pm 2.2$ & $20 \pm 5.5$ & 4.9 \\
\hline 28 & & $2.1 \pm 0.1$ & $10 \pm 1$ & 4.8 \\
\hline 29 & & $3.1 \pm 1.3$ & $26 \pm 7$ & 8.4 \\
\hline 30 & & $1.4 \pm 1.0$ & $47 \pm 1$ & 33.6 \\
\hline 31 & & $1.8 \pm 0.3$ & $18 \pm 9$ & 5.6 \\
\hline
\end{tabular}

The importance of the 1,2,4-oxadiazole moiety for antiviral activity was investigated by the synthesis of a number of alternative 5-membered heteroaryl derivatives (Table 4). Except for compound 38 with a 1,3,4-oxadiazole moiety, which was 3-fold less active, other derivatives containing a 1,2,4-oxadiazole (35), a 1,2,4-thiadiazole (46) or an isoxazole (49) showed a similar biological profile as compound 8, indicating that the 1,2,4-oxadiazole ring is not involved in crucial interactions for antiviral activity, but can be considered as a linker.

\subsubsection{Broad-Spectrum Antiviral Activity}

The primary SARS-CoV-2 screening focused on the B.1 (Wuhan) lineage. However, several variants of SARS-CoV-2 have emerged and are circulating worldwide, and more will emerge in the future. Therefore, it is important to determine the activity of antiviral agents against the variants of concerns (VoCs). Interestingly, compound $\mathbf{1}$ showed a similar activity against the B.1 lineage and the B.1.1.7 (UK or Alpha variant) and B.1.617.2 (Indian or Delta variant) lineages in Vero E6 cells (Table 5). In addition, compound $\mathbf{1}$ is equally 
active against other $\beta$-coronaviruses, such as SARS-CoV- 1 and the Middle East respiratory syndrome coronavirus (MERS-CoV).

Table 4. Antiviral activity and cytotoxicity of compounds $8,35,38,46$, and 49 .

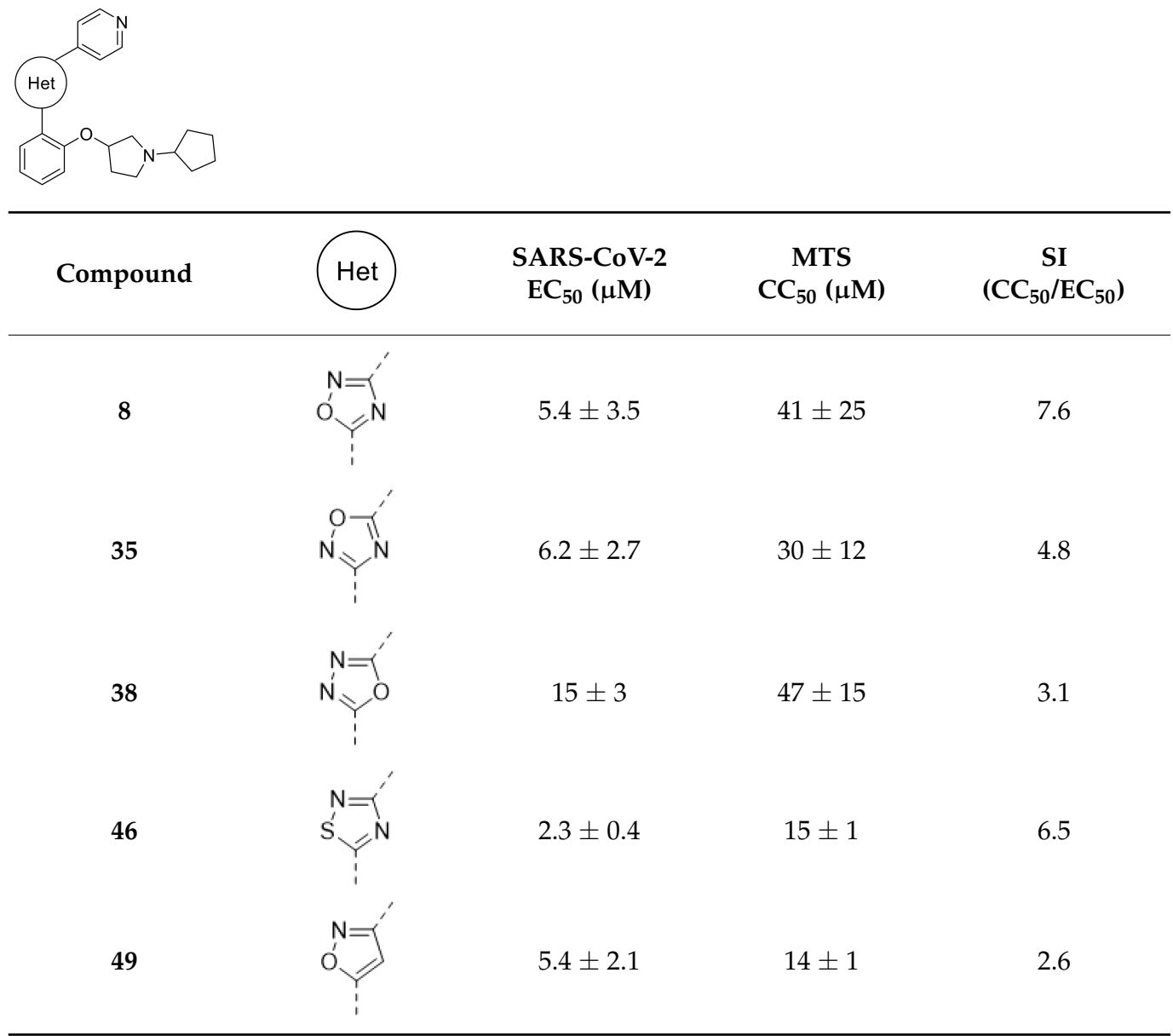

Table 5. Spectrum of antiviral activity of compound $\mathbf{1 .}$

\begin{tabular}{|c|c|c|c|c|c|c|}
\hline $\begin{array}{l}\text { SARS-CoV-2 }^{a} \\
\text { EC }_{50}(\mu \mathrm{M})\end{array}$ & $\begin{array}{c}\text { B.1.1.7 } \\
\text { EC }_{50}(\mu \mathrm{M})\end{array}$ & $\begin{array}{l}\text { B.1.617.2 } \\
\text { EC }_{50}(\mu \mathrm{M})\end{array}$ & $\begin{array}{l}\text { SARS-CoV-1 a } \\
\text { EC }_{50}(\mu \mathrm{M})\end{array}$ & $\begin{array}{c}\text { VeroE6 } \\
\mathrm{CC}_{50}(\mu \mathrm{M})\end{array}$ & $\begin{array}{c}\text { MERS }^{\mathrm{b}} \\
\mathrm{EC}_{50}(\mu \mathrm{M})\end{array}$ & $\begin{array}{c}\text { Huh7 } \\
\mathrm{CC}_{50}(\mu \mathrm{M})\end{array}$ \\
\hline $4.7 \pm 3.0$ & $3.0 \pm 1.0$ & $4.0 \pm 2.0$ & $4.2 \pm 0.2$ & $21 \pm 11$ & 5.0 & $>20$ \\
\hline
\end{tabular}

a Antiviral activity in VeroE6 cells in presence of P-gp inhibitor. ${ }^{\mathrm{b}}$ Antiviral activity in Huh-7 cells.

\subsubsection{Mode of Action Investigation}

In order to exclude a non-specific antiviral effect, we tested compound $\mathbf{1}$ against the SARS-CoV-2 unrelated Chikungunya virus in Vero A cells [27]. The complete lack of antiviral activity of compound $\mathbf{1}\left(\mathrm{EC}_{50}>100 \mu \mathrm{M}\right)$ in this assay demonstrates a specific antiviral effect for coronavirus. However, since compounds were evaluated in a cell-based assay, the exact molecular target responsible for the antiviral activity remains elusive. In an effort to pinpoint the exact target, the inhibitory effect of compound 1 against various coronavirus enzymes such as SARS-CoV-2 Mpro, SARS-CoV-2 nsp14 (N7-methyltransferase activity), and the SARS-CoV-2 replication-transcription complex was studied. However, even at the highest tested concentration of $100 \mu \mathrm{M}$, compound $\mathbf{1}$ did not show any inhibitory activity on these enzymes.

To evaluate if compound $\mathbf{1}$ acted at the level of the virus entry, a SARS-CoV-2 and MERS pseudovirus neutralization assay was performed. In both assays, compound 1 was able to block the virus entry with an $\mathrm{EC}_{50}$ value of $1.25 \mu \mathrm{M}$ and $3.4 \mu \mathrm{M}$, respectively. Compound 1 was found to be inactive against human proteases involved in SARS-CoV-2 
entry such as cathepsin L, cathepsin B, TMPRSS2, and furin. Altogether, this first set of data demonstrated that hit $\mathbf{1}$ exerts its antiviral activity via interference with the viral entry mechanism. More research is required to determine if this virus entry inhibition is mediated by a viral or a host target protein.

\section{Materials and Methods}

3.1. Chemistry

3.1.1. General Methods

All reagents and solvents were purchased from Sigma-Aldrich (Saint Louis, MO, USA), TCI (TCI Europe N.V., Zwijndrecht, Belgium), Combi-Blocks (San Diego, CA, USA) and used without further purification. All the reactions were monitored by thin-layer chromatography (TLC) or liquid chromatography-mass spectrometry (LCMS). TLC was carried out with Sigma-Aldrich silica gel (254 nm) plates (cat ref 99571-25EA) and TLC plates were revealed with UV light, $\mathrm{KMnO}_{4}, p$-anisaldehyde, or ninhydrin solutions. LCMS analysis was performed on an Agilent 1260 Infinity II UPLC machine (Agilent Technologies, Santa Clara, CA, USA) with a YMC-Triart C18 column (YMC CO., Kyoto, Japan). Flash chromatography purifications were performed on Biotage prepacked silica gel columns using Biotage Isolera instruments (Biotage, Upsala, Sweden). Reversed-phase preparative highpressure liquid chromatography (HPLC) purification of final analogs was performed on a Waters Autopurification instrument (Waters Corporation, Milford, MA, USA) with MS- and UV-triggered collection operating at ambient temperature and at a flow rate of $16 \mathrm{~mL} / \mathrm{min}$. The identity of all compounds with reported biological activity was confirmed by NMR spectroscopy and low-resolution mass spectrometry (MS). The purity of all compounds with reported biological activity was $\geq 95 \%$ as determined by NMR and ultraperformance liquid chromatography (UPLC). Proton NMR spectra were recorded on a 300 or $400 \mathrm{MHz}$ Bruker spectrometer (Bruker Corporation, Billerica, MA, USA) using TMS as internal standard, whereas carbon NMR spectra were recorded on a Bruker Avance $600 \mathrm{MHz}$ instrument (Bruker Corporation, Billerica, MA, USA) $\left({ }^{13} \mathrm{C}\right.$ NMR, $\left.150 \mathrm{MHz}\right)$ using DMSO- $d_{6}(39.5 \mathrm{ppm})$ as internal standard. Proton and carbon chemical shifts $(\delta)$ are reported in parts per million (ppm). Abbreviations used are: $\mathrm{s}=$ singlet, $\mathrm{d}=$ doublet, $\mathrm{t}=$ triplet, $\mathrm{q}=$ quartet, $\mathrm{m}=$ multiplet, br $=$ broad. Coupling constants are expressed in Hz. Low-resolution mass spectral data were obtained using a Waters H-Class UPLC (Waters Corporation, Milford, MA, USA) with a Waters Acquity UPLC BEH C18 $1.7 \mu \mathrm{m}, 2.1 \mathrm{~mm} \times 30 \mathrm{~mm}$ column (Waters Corporation, Milford, MA, USA), equipped with an Acquity UPLC PDA Detector (Waters Corporation, Milford, MA, USA), an Acquity UPLC ELS Detector (Waters Corporation, Milford, MA, USA)and an Acquity TQ Detector (ESI/ESCi) (Waters Corporation, Milford, MA, USA).

\subsubsection{2-(3-(Pyridin-4-yl)-1,2,4-oxadiazol-5-yl)phenol (4)}

A solution of $N^{\prime}$-hydroxypyridine-4-carboxamidine $(0.500 \mathrm{~g}, 3.65 \mathrm{mmol}, 1 \mathrm{eq})$ and salicylaldehyde $(0.461 \mathrm{~mL}, 4.38 \mathrm{mmol}, 1.2 \mathrm{eq})$ in $\mathrm{EtOH}(1.5 \mathrm{~mL})$ was irradiated in a microwave oven at $160{ }^{\circ} \mathrm{C}$ for $1 \mathrm{~h}$. After cooling to room temperature, the beige solid was filtered, washed with cold ethanol and dried under high vacuum to afford $0.228 \mathrm{~g}(26 \%)$ of the title compound. LC-MS (ESI, $m / z): 240[\mathrm{M}+\mathrm{H}]^{+} .{ }^{1} \mathrm{H}$ NMR $\left(400 \mathrm{MHz}, \mathrm{DMSO}-d_{6}\right)$ $\delta$ ppm $10.69(\mathrm{~s}, 1 \mathrm{H}), 8.84(\mathrm{~d}, J=6.1 \mathrm{~Hz}, 2 \mathrm{H}), 8.02-8.05(\mathrm{~m}, 3 \mathrm{H}), 7.52-7.60(\mathrm{~m}, 1 \mathrm{H}), 7.15$ $(\mathrm{d}, J=8.5 \mathrm{~Hz}, 1 \mathrm{H}), 7.06(\mathrm{t}, J=7.6 \mathrm{~Hz}, 1 \mathrm{H})$.

\subsubsection{5-(2-((1-Phenethylpyrrolidin-3-yl)oxy)phenyl)-3-(pyridin-4-yl)-1,2,4-oxadiazole (1)}

A mixture of pyrrolidin-3-ol $(0.100 \mathrm{~g}, 1.11 \mathrm{mmol}, 1 \mathrm{eq}),(2-\mathrm{bromoethyl})$ benzene (0.307 mL, $2.23 \mathrm{mmol}, 2 \mathrm{eq})$ and $\mathrm{K}_{2} \mathrm{CO}_{3}(0.769 \mathrm{~g}, 5.57 \mathrm{mmol}, 5 \mathrm{eq})$ in toluene $(5 \mathrm{~mL})$ was heated at $110{ }^{\circ} \mathrm{C}$ overnight. The reaction mixture was concentrated under reduced pressure. The residue was taken up with $1 \mathrm{~N} \mathrm{HCl}$ and extracted with $\mathrm{CH}_{2} \mathrm{Cl}_{2}$ twice. The aqueous phase was basified by the addition of $\mathrm{K}_{2} \mathrm{CO}_{3}$ and extracted with $\mathrm{CH}_{2} \mathrm{Cl}_{2}$. The organic phase was dried over $\mathrm{MgSO}_{4}$, filtered, and concentrated under reduced pressure to afford $0.130 \mathrm{~g}(61 \%)$ of 1-(2-phenylethyl)pyrrolidin-3-ol as a white solid. LC-MS (ESI, $m / z)$ : 
$192[\mathrm{M}+\mathrm{H}]^{+} .{ }^{1} \mathrm{H}$ NMR $\left(400 \mathrm{MHz}, \mathrm{DMSO}-d_{6}\right) \delta \mathrm{ppm} 7.12-7.33(\mathrm{~m}, 5 \mathrm{H}), 4.67(\mathrm{~d}, J=4.6 \mathrm{~Hz}$, $1 \mathrm{H}), 4.12-4.23(\mathrm{~m}, 1 \mathrm{H}), 2.65-2.80(\mathrm{~m}, 3 \mathrm{H}), 2.55-2.64(\mathrm{~m}, 3 \mathrm{H}), 2.41-2.48(\mathrm{~m}, 1 \mathrm{H}), 2.34(\mathrm{~m}, 1 \mathrm{H})$, 1.90-2.02 (m, 1H), 1.45-1.58 (m, 1H).

To a solution of $4(0.050 \mathrm{~g}, 0.209 \mathrm{mmol}, 1 \mathrm{eq}), 1$-(2-phenylethyl)pyrrolidin-3-ol (0.056 g, $0.293 \mathrm{mmol}, 1.4 \mathrm{eq}$ ) and 1,1'-(azodicarbonyl)dipiperidine $(0.075 \mathrm{~g}, 0.293 \mathrm{mmol}, 1.4 \mathrm{eq})$ in THF (2.2 mL) was added $n \mathrm{Bu}_{3} \mathrm{P}(0.079 \mathrm{~mL}, 0.293 \mathrm{mmol}, 1.4 \mathrm{eq})$. The reaction mixture was stirred at room temperature for $2 \mathrm{~d}$ and was concentrated under reduced pressure. The residue was purified by flash chromatography on silica gel using a gradient of $\mathrm{MeOH}$ (0-15\%) in $\mathrm{CH}_{2} \mathrm{Cl}_{2}$. A second purification by flash chromatography on silica gel using a gradient of $\mathrm{MeOH}(0-7 \%)$ in $\mathrm{CH}_{2} \mathrm{Cl}_{2}$ followed by trituration with $\mathrm{Et}_{2} \mathrm{O}$ furnished $0.045 \mathrm{~g}$ (51\%) of the title compound as a white solid. LC-MS (ESI, $m / z): 413[\mathrm{M}+\mathrm{H}]^{+}$. ${ }^{1} \mathrm{H} \mathrm{NMR}$ $\left(400 \mathrm{MHz}, \mathrm{DMSO}-\mathrm{d}_{6}\right) \delta 8.84(\mathrm{~d}, J=4.8 \mathrm{~Hz}, 2 \mathrm{H}), 8.12(\mathrm{~d}, J=7.3 \mathrm{~Hz}, 1 \mathrm{H}), 8.02(\mathrm{~d}, J=5.7 \mathrm{~Hz}$, $2 \mathrm{H}), 7.68(\mathrm{t}, J=7.8 \mathrm{~Hz}, 1 \mathrm{H}), 7.11-7.32(\mathrm{~m}, 7 \mathrm{H}), 5.11(\mathrm{~m}, 1 \mathrm{H}), 3.06(\mathrm{~m}, 1 \mathrm{H}), 2.74-2.86(\mathrm{~m}$, $4 \mathrm{H}), 2.67(\mathrm{~m}, 2 \mathrm{H}), 2.59(\mathrm{~m}, 1 \mathrm{H}), 2.34(\mathrm{~m}, 1 \mathrm{H}), 1.94(\mathrm{~m}, 1 \mathrm{H})$ (Figure $\mathrm{S} 1) .{ }^{13} \mathrm{C} \mathrm{NMR}(150 \mathrm{MHz}$, DMSO- $\left.d_{6}\right) \delta 175.89,166.29,156.64,150.99,140.38,135.10,133.74,131.63,128.65,128.27$, $125.92,121.08,120.96,114.81,112.68,77.72,59.63,57.32,52.50,34.53,31.87$ (Figure S2).

\subsubsection{5-[2-[(3R)-1-(2-Phenylethyl)pyrrolidin-3-yl]oxyphenyl]-3-(4-pyridyl)-1,2,4-oxadiazole (1a)}

The title compound was prepared similarly to 1 using (3S)-1-(2-phenylethyl)pyrrolidin3-ol instead of pyrrolidin-3-ol (Figures S3 and S4).

3.1.5. 5-[2-[(3S)-1-(2-Phenylethyl)pyrrolidin-3-yl]oxyphenyl]-3-(4-pyridyl)-1,2,4-oxadiazole (1b)

The title compound was prepared similarly to 1 using (3R)-1-(2-phenylethyl)pyrrolidin3-ol instead of pyrrolidin-3-ol (Figure S5).

\subsubsection{5-[2-(1-Cyclopentylpyrrolidin-3-yl)oxyphenyl]-3-(4-pyridyl)-1,2,4-oxadiazole (8)}

A mixture of pyrrolidin-3-ol $(0.100 \mathrm{~g}, 1.11 \mathrm{mmol}, 1 \mathrm{eq})$, bromocyclopentane $(0.244 \mathrm{~mL}$, $2.23 \mathrm{mmol}, 2 \mathrm{eq})$ and $\mathrm{K}_{2} \mathrm{CO}_{3}(0.769 \mathrm{~g}, 5.57 \mathrm{mmol}, 5 \mathrm{eq})$ in toluene $(5 \mathrm{~mL})$ was heated at $110{ }^{\circ} \mathrm{C}$ overnight. The reaction mixture was concentrated under reduced pressure. The residue was taken up with $1 \mathrm{~N} \mathrm{HCl}$ and extracted with $\mathrm{CH}_{2} \mathrm{Cl}_{2}$ twice. The aqueous phase was basified by the addition of $\mathrm{K}_{2} \mathrm{CO}_{3}$ and extracted with $\mathrm{CH}_{2} \mathrm{Cl}_{2}$. The organic phase was dried over $\mathrm{MgSO}_{4}$, filtered, and concentrated under reduced pressure to afford $0.081 \mathrm{~g}$ (47\%) of 1-cyclopentylpyrrolidin-3-ol as a white solid. LC-MS (ESI, $m / z): 156[\mathrm{M}+\mathrm{H}]^{+}$.

The title compound was prepared similarly to 1 using 1-cyclopentylpyrrolidin-3-ol instead of 1-(2-phenylethyl)pyrrolidin-3-ol. LC-MS (ESI, $m / z): 377[\mathrm{M}+\mathrm{H}]^{+}$. ${ }^{1} \mathrm{H}$ NMR $\left(400 \mathrm{MHz}, \mathrm{DMSO}-d_{6}\right) \delta 8.84(\mathrm{~m}, 2 \mathrm{H}), 8.12(\mathrm{dd}, J=1.5,7.6 \mathrm{~Hz}, 1 \mathrm{H}), 8.02(\mathrm{~m}, 2 \mathrm{H}), 7.68(\mathrm{~m}, 1 \mathrm{H})$, $7.26(\mathrm{~d}, J=8.5 \mathrm{~Hz}, 1 \mathrm{H}), 7.19(\mathrm{t}, J=7.6 \mathrm{~Hz}, 1 \mathrm{H}), 5.07(\mathrm{t}, J=6.7 \mathrm{~Hz}, 1 \mathrm{H}), 3.02(\mathrm{~m}, 1 \mathrm{H}), 2.65-2.77$ $(\mathrm{m}, 2 \mathrm{H}), 2.43-2.48(\mathrm{~m}, 2 \mathrm{H}), 2.33(\mathrm{~m}, 1 \mathrm{H}), 1.92(\mathrm{~m}, 1 \mathrm{H}), 1.73(\mathrm{~m}, 2 \mathrm{H}), 1.33-1.67(\mathrm{~m}, 6 \mathrm{H})$ (Figure S6).

3.1.7. 5-[2-[1-(Cyclopentylmethyl)pyrrolidin-3-yl]oxyphenyl]-3-(4-pyridyl)-1,2,4-oxadiazole (9)

To a solution of $4(0.165 \mathrm{~g}, 0.690 \mathrm{mmol}, 1 \mathrm{eq})$ in THF $(2.2 \mathrm{~mL})$ were added DIAD (0.217 mL, $1.03 \mathrm{mmol}, 1.5 \mathrm{eq})$, 1-Boc-3-hydroxypyrrolidine (0.200 g, $1.03 \mathrm{mmol}, 1.5 \mathrm{eq})$ and $\mathrm{PPh}_{3}(0.271 \mathrm{~g}, 1.03 \mathrm{mmol}, 1.5 \mathrm{eq})$. The reaction mixture was stirred at room temperature overnight. The reaction mixture was diluted with EtOAc and washed with water. The phases were separated. The organic phase was washed with $1 \mathrm{~N} \mathrm{NaOH}$, dried over $\mathrm{MgSO}_{4}$, filtered, and concentrated under reduced pressure. The residue was purified by flash chromatography on silica gel using a gradient of EtOAc (20-60\%) in heptane to afford $0.276 \mathrm{~g}(98 \%)$ of tert-butyl 3-[2-[3-(4-pyridyl)-1,2,4-oxadiazol-5-yl]phenoxy]pyrrolidine-1carboxylate as a white solid. LC-MS (ESI, $m / z): 409[\mathrm{M}+\mathrm{H}]^{+}$.

To a mixture of tert-butyl 3-[2-[3-(4-pyridyl)-1,2,4-oxadiazol-5-yl]phenoxy]pyrrolidine1-carboxylate $(0.276 \mathrm{~g}, 0.676 \mathrm{mmol}, 1 \mathrm{eq})$ in dioxane $(2 \mathrm{~mL})$ was added $4 \mathrm{~N} \mathrm{HCl}$ in dioxane (1.01 mL; $4.04 \mathrm{mmol}, 6 \mathrm{eq})$. The reaction mixture was stirred at room temperature for $4 \mathrm{~h}$ 
and was concentrated under reduced pressure to afford quantitatively 3-(4-pyridyl)-5-(2pyrrolidin-3-yloxyphenyl)-1,2,4-oxadiazole dihydrochloride as a white solid.

To a solution of 3-(4-pyridyl)-5-(2-pyrrolidin-3-yloxyphenyl)-1,2,4-oxadiazole dihydrochloride $(0.100 \mathrm{~g}, 0.262 \mathrm{mmol}, 1 \mathrm{eq})$ in DMF $(1 \mathrm{~mL})$ were added $\mathrm{K}_{2} \mathrm{CO}_{3}(0.073 \mathrm{~g}$, $0.525 \mathrm{mmol}, 2 \mathrm{eq})$ and iodomethylcyclopentane $(0.053 \mathrm{~mL}, 0.393 \mathrm{mmol}, 1.5 \mathrm{eq})$. The reaction mixture was heated at $80^{\circ} \mathrm{C}$ for $2 \mathrm{~h}$. After cooling to room temperature, the reaction mixture was diluted with water and extracted with $\mathrm{CH}_{2} \mathrm{Cl}_{2}$. The organic phase was dried over $\mathrm{MgSO}_{4}$, filtered, and concentrated under reduced pressure. The residue was purified by flash chromatography on silica gel using a gradient of $\mathrm{MeOH}(0-25 \%)$ in $\mathrm{CH}_{2} \mathrm{Cl}_{2}$. A second purification by flash chromatography on $\mathrm{C} 18$ using a gradient of $\mathrm{CH}_{3} \mathrm{CN}(5-100 \%)$ in water furnished $0.043 \mathrm{~g}(40 \%)$ of the title compound as a beige solid. LC-MS (ESI, $m / z)$ : $391[\mathrm{M}+\mathrm{H}]^{+} .{ }^{1} \mathrm{H}$ NMR $\left(400 \mathrm{MHz}, \mathrm{CD}_{3} \mathrm{OD}\right) \delta 8.78(\mathrm{~m}, 2 \mathrm{H}), 8.14(\mathrm{~m}, 3 \mathrm{H}), 7.66(\mathrm{~m}, 1 \mathrm{H})$, $7.20(\mathrm{~m}, 2 \mathrm{H}), 5.12(\mathrm{~m}, 1 \mathrm{H}), 3.14(\mathrm{~m}, 1 \mathrm{H}), 2.93(\mathrm{~m}, 1 \mathrm{H}), 2.85(\mathrm{~m}, 1 \mathrm{H}), 2.70(\mathrm{~m}, 1 \mathrm{H}), 2.45-2.60$ $(\mathrm{m}, 2 \mathrm{H}), 2.40(\mathrm{~m}, 1 \mathrm{H}), 2.01-2.18(\mathrm{~m}, 2 \mathrm{H}), 1.83(\mathrm{~m}, 2 \mathrm{H}), 1.50-1.72(\mathrm{~m}, 4 \mathrm{H}), 1.24(\mathrm{~m}, 2 \mathrm{H})$ (Figure S7). ${ }^{13} \mathrm{C}$ NMR $\left(150 \mathrm{MHz}\right.$, DMSO- $\left.d_{6}\right) \delta 175.55,166.30,156.68,150.97,135.07,133.76$, $131.57,121.07,120.91,114.83,112.70,77.80,61.46,59.96,52.84,38.47,31.86,30.80,24.81$ (Figure S8).

\subsubsection{5-[2-[(1-Cyclopentylpyrrolidin-3-yl)methoxy]phenyl]-3-(4-pyridyl)-1,2,4-oxadiazole (10)}

To a solution of $4(0.300 \mathrm{~g}, 1.25 \mathrm{mmol}, 1 \mathrm{eq})$ in THF $(4 \mathrm{~mL})$ were added DIAD (0.394 mL, $1.88 \mathrm{mmol}, 1.5 \mathrm{eq}$ ), tert-butyl 3-(hydroxymethyl)pyrrolidine-1-carboxylate $(0.379 \mathrm{~g}, 1.88 \mathrm{mmol}, 1.5 \mathrm{eq})$ and $\mathrm{PPh}_{3}(0.493 \mathrm{~g}, 1.88 \mathrm{mmol}, 1.5 \mathrm{eq})$. The reaction mixture was stirred at room temperature overnight. The reaction mixture was diluted with EtOAc and washed with water. The phases were separated. The organic phase was washed with $1 \mathrm{~N} \mathrm{NaOH}$, dried over $\mathrm{MgSO}_{4}$, filtered, and concentrated under reduced pressure. The residue was purified by flash chromatography on silica gel using a gradient of EtOAc (20-60\%) in heptane to afford 0.529 g (99\%) of tert-butyl 3-[[2-[3-(4-pyridyl)-1,2,4oxadiazol-5-yl]phenoxy]methyl]pyrrolidine-1-carboxylate as a white solid. LC-MS (ESI, $m / z): 423[\mathrm{M}+\mathrm{H}]^{+}$.

To a mixture of tert-butyl 3-[[2-[3-(4-pyridyl)-1,2,4-oxadiazol-5-yl]phenoxy] methyl]pyrrolidine-1-carboxylate $(0.529 \mathrm{~g}, 1.25 \mathrm{mmol}, 1 \mathrm{eq})$ in dioxane $(4 \mathrm{~mL})$ was added $4 \mathrm{~N} \mathrm{HCl}$ in dioxane $(1.01 \mathrm{~mL} ; 4.04 \mathrm{mmol}, 3.2 \mathrm{eq})$. The reaction mixture was stirred at room temperature overnight and was concentrated under reduced pressure to afford quantitatively 3-(4-pyridyl)-5-[2-(pyrrolidin-3-ylmethoxy)phenyl]-1,2,4-oxadiazole dihydrochloride as a white solid.

To a solution of 3-(4-pyridyl)-5-[2-(pyrrolidin-3-ylmethoxy)phenyl]-1,2,4-oxadiazole dihydrochloride $(0.100 \mathrm{~g}, 0.253 \mathrm{mmol}, 1 \mathrm{eq})$ in DMF $(2 \mathrm{~mL})$ were added $\mathrm{K}_{2} \mathrm{CO}_{3}(0.175 \mathrm{~g}$, $1.26 \mathrm{mmol}, 5 \mathrm{eq}), \mathrm{NaI}(0.019 \mathrm{~g}, 0.127 \mathrm{mmol}, 0.5 \mathrm{eq})$ and bromocyclopentane $(0.083 \mathrm{~mL}$, $0.759 \mathrm{mmol}, 3 \mathrm{eq}$ ). The reaction mixture was heated at $80^{\circ} \mathrm{C}$ for $2 \mathrm{~h}$. After cooling to room temperature, the reaction mixture was diluted with water and extracted with $\mathrm{CH}_{2} \mathrm{Cl}_{2}$. The organic phase was dried over $\mathrm{MgSO}_{4}$, filtered, and concentrated under reduced pressure. The residue was purified by flash chromatography on silica gel using a gradient of $\mathrm{MeOH}$ $(0-25 \%)$ in $\mathrm{CH}_{2} \mathrm{Cl}_{2}$ to afford $0.026 \mathrm{~g}(26 \%)$ of the title compound as a beige solid. LC-MS (ESI, $m / z): 391[\mathrm{M}+\mathrm{H}]^{+} .{ }^{1} \mathrm{H}$ NMR $\left(400 \mathrm{MHz}, \mathrm{CD}_{3} \mathrm{OD}\right) \delta 8.81(\mathrm{~d}, J=5.8 \mathrm{~Hz}, 2 \mathrm{H}), 8.24$ $(\mathrm{m}, 1 \mathrm{H}), 8.14(\mathrm{~m}, 2 \mathrm{H}), 7.71(\mathrm{~m}, 1 \mathrm{H}), 7.33(\mathrm{~d}, J=8.5 \mathrm{~Hz}, 1 \mathrm{H}), 7.24(\mathrm{t}, J=7.6 \mathrm{~Hz}, 1 \mathrm{H}), 4.27-4.39$ $(\mathrm{m}, 2 \mathrm{H}), 3.75(\mathrm{~m}, 1 \mathrm{H}), 3.36-3.62(\mathrm{~m}, 4 \mathrm{H}), 3.07(\mathrm{~m}, 1 \mathrm{H}), 2.38(\mathrm{~m}, 1 \mathrm{H}), 2.18(\mathrm{~m}, 3 \mathrm{H}), 1.86$ $(\mathrm{m}, 2 \mathrm{H}), 1.71(\mathrm{~m}, 4 \mathrm{H})$ (Figure S9). ${ }^{13} \mathrm{C}$ NMR $\left(150 \mathrm{MHz}, \mathrm{DMSO}-d_{6}\right) \delta 175.57,166.49,157.41$, $151.05,135.29$, 133.70, 131.31, 121.41, 121.12, 114.07, 112.23, 69.70, 65.77, 54.61, 52.10, 36.15, 29.03, 26.02, 23.58 (Figure S10).

3.1.9. 5-[2-[[1-(Cyclopentylmethyl)pyrrolidin-3-yl]methoxy]phenyl]-3-(4-pyridyl)-1,2,4oxadiazole (11)

The title compound was prepared similarly to $\mathbf{1 0}$ using iodomethylcyclopentane instead of bromocyclopentane. LC-MS (ESI, $m / z): 405[\mathrm{M}+\mathrm{H}]^{+} .{ }^{1} \mathrm{H}$ NMR $(400 \mathrm{MHz}$, 
$\left.\mathrm{CD}_{3} \mathrm{OD}\right) \delta 8.80(\mathrm{~m}, 2 \mathrm{H}), 8.20(\mathrm{dd}, J=1.5,7.5 \mathrm{~Hz}, 1 \mathrm{H}), 8.15(\mathrm{~m}, 2 \mathrm{H}), 7.68(\mathrm{~m}, 1 \mathrm{H}), 7.30$ $(\mathrm{d}, J=8.5 \mathrm{~Hz}, 1 \mathrm{H}), 7.21(\mathrm{t}, J=7.5 \mathrm{~Hz}, 1 \mathrm{H}), 4.15-\mathrm{do} 4.32(\mathrm{~m}, 2 \mathrm{H}), 3.12(\mathrm{~m}, 1 \mathrm{H}), 2.85-3.04$ $(\mathrm{m}, 3 \mathrm{H}), 2.80(\mathrm{~m}, 2 \mathrm{H}), 2.08-2.30(\mathrm{~m}, 2 \mathrm{H}), 1.81-2.00(\mathrm{~m}, 3 \mathrm{H}), 1.52-1.73(\mathrm{~m}, 4 \mathrm{H}), 1.17-1.39$ $(\mathrm{m}, 3 \mathrm{H})$ (Figure S11). ${ }^{13} \mathrm{C}$ NMR $\left(150 \mathrm{MHz}, \mathrm{DMSO}-d_{6}\right) \delta 175.71,166.40,157.68,151.00,135.22$, $133.74,131.30,121.17,121.08,114.06,112.24,71.06,60.66,56.60,53.53,37.78,36.39,30.77$, 26.45, 24.75 (Figure S12).

\subsubsection{5-[2-[(1-Cyclopentyl-4-piperidyl)oxy]phenyl]-3-(4-pyridyl)-1,2,4-oxadiazole (12)}

To a solution of $4(0.165 \mathrm{~g}, 0.690 \mathrm{mmol}, 1 \mathrm{eq})$ in THF $(2.2 \mathrm{~mL})$ were added DIAD (0.217 mL, $1.03 \mathrm{mmol}, 1.5 \mathrm{eq}), 1$-Boc-4-hydroxypiperidine $(0.213 \mathrm{~g}, 1.03 \mathrm{mmol}, 1.5 \mathrm{eq})$ and $\mathrm{PPh}_{3}(0.271 \mathrm{~g}, 1.03 \mathrm{mmol}, 1.5 \mathrm{eq})$. The reaction mixture was stirred at room temperature overnight. The reaction mixture was diluted with EtOAc and washed with water. The phases were separated. The organic phase was washed with $1 \mathrm{~N} \mathrm{NaOH}$, dried over $\mathrm{MgSO}_{4}$, filtered, and concentrated under reduced pressure. The residue was purified by flash chromatography on silica gel using a gradient of EtOAc (20-60\%) in heptane to afford $0.276 \mathrm{~g}$ (95\%) of tert-butyl 4-[2-[3-(4-pyridyl)-1,2,4-oxadiazol-5-yl]phenoxy]piperidine-1carboxylate as a white solid. LC-MS (ESI, $m / z): 423[\mathrm{M}+\mathrm{H}]^{+}$.

To a mixture of tert-butyl 4-[[2-[3-(4-pyridyl)-1,2,4-oxadiazol-5-yl]phenoxy]piperidine1-carboxylate $(0.271 \mathrm{~g}, 0.642 \mathrm{mmol}, 1 \mathrm{eq})$ in dioxane $(2 \mathrm{~mL})$ was added $4 \mathrm{~N} \mathrm{HCl}$ in dioxane $(0.962 \mathrm{~mL} ; 3.85 \mathrm{mmol}, 6 \mathrm{eq})$. The reaction mixture was stirred at room temperature overnight and was concentrated under reduced pressure to afford quantitatively 5-[2-(4piperidyloxy)phenyl]-3-(4-pyridyl)-1,2,4-oxadiazole dihydrochloride as a white solid.

To a solution of 5-[2-(4-piperidyloxy)phenyl]-3-(4-pyridyl)-1,2,4-oxadiazole dihydrochloride $(0.100 \mathrm{~g}, 0.253 \mathrm{mmol}, 1 \mathrm{eq})$ in $\mathrm{DMF}(2 \mathrm{~mL})$ were added $\mathrm{K}_{2} \mathrm{CO}_{3}(0.175 \mathrm{~g}, 1.26 \mathrm{mmol}, 5 \mathrm{eq})$, $\mathrm{NaI}(0.019 \mathrm{~g}, 0.127 \mathrm{mmol}, 0.5 \mathrm{eq})$ and bromocyclopentane $(0.083 \mathrm{~mL}, 0.759 \mathrm{mmol}, 3 \mathrm{eq})$. The reaction mixture was heated at $80{ }^{\circ} \mathrm{C}$ for $2 \mathrm{~h}$. After cooling to room temperature, the reaction mixture was diluted with water and extracted with $\mathrm{CH}_{2} \mathrm{Cl}_{2}$. The organic phase was dried over $\mathrm{MgSO}_{4}$, filtered, and concentrated under reduced pressure. The residue was purified by flash chromatography on silica gel using a gradient of $\mathrm{MeOH}(1-25 \%)$ in $\mathrm{CH}_{2} \mathrm{Cl}_{2}$ to afford $0.056 \mathrm{~g}(57 \%)$ of the title compound as a beige solid. LC-MS (ESI, $m / z): 391[\mathrm{M}+\mathrm{H}]^{+} .{ }^{1} \mathrm{H}$ $\operatorname{NMR}\left(400 \mathrm{MHz}, \mathrm{CD}_{3} \mathrm{OD}\right) \delta 8.80(\mathrm{~m}, 2 \mathrm{H}), 8.21$ (dd, $\left.J=1.5,7.9 \mathrm{~Hz}, 1 \mathrm{H}\right), 8.16(\mathrm{~m}, 2 \mathrm{H}), 7.68$ $(\mathrm{m}, 1 \mathrm{H}), 7.36(\mathrm{~d}, J=8.2 \mathrm{~Hz}, 1 \mathrm{H}), 7.22(\mathrm{t}, J=7.9 \mathrm{~Hz}, 1 \mathrm{H}), 4.97(\mathrm{~m}, 1 \mathrm{H}), 3.23(\mathrm{~m}, 2 \mathrm{H})$, 3.03-3.18 (m, 3H), $2.17(\mathrm{~m}, 4 \mathrm{H}), 2.07(\mathrm{~m}, 2 \mathrm{H}), 1.79(\mathrm{~m}, 2 \mathrm{H}), 1.63(\mathrm{~m}, 4 \mathrm{H})$ (Figure S13). ${ }^{13} \mathrm{C}$ NMR $\left(150 \mathrm{MHz}, \mathrm{DMSO}-d_{6}\right) \delta 175.70,166.48,156.00,151.00,135.11,133.78,131.56,121.29,121.14$, $115.45,113.20,71.21,66.65,47.47,28.87,23.66$ (Figure S14).

\subsubsection{5-(2-(2-Bromoethoxy)phenyl)-3-(pyridin-4-yl)-1,2,4-oxadiazole (7)}

To a solution of $4(3.0 \mathrm{~g}, 12.5 \mathrm{mmol}, 1 \mathrm{eq})$ in DMF $(30 \mathrm{~mL})$ were added $\mathrm{K}_{2} \mathrm{CO}_{3}(3.5 \mathrm{~g}$, $25.1 \mathrm{mmol}, 2 \mathrm{eq})$ and 1,2-dibromoethane (3.24 g, $37.6 \mathrm{mmol}, 3 \mathrm{eq})$. The reaction mixture was heated at $80{ }^{\circ} \mathrm{C}$ for $2 \mathrm{~h}$. After cooling to room temperature, the reaction mixture was poured into ice/water. The resulting precipitate was filtered and dried under high vacuum to afford $2.0 \mathrm{~g}(46 \%)$ of the title compound as a beige solid. ${ }^{1} \mathrm{H} \mathrm{NMR}(300 \mathrm{MHz}$, DMSO- $\left.d_{6}\right) \delta 8.84(\mathrm{~d}, J=5.9 \mathrm{~Hz}, 2 \mathrm{H}), 8.12(\mathrm{~m}, 1 \mathrm{H}), 8.03(\mathrm{~d}, J=5.8 \mathrm{~Hz}, 2 \mathrm{H}), 7.70(\mathrm{~m}, 1 \mathrm{H}), 7.35$ $(\mathrm{d}, J=8.4 \mathrm{~Hz}, 1 \mathrm{H}), 7.23(\mathrm{t}, J=7.5 \mathrm{~Hz}, 1 \mathrm{H}), 4.55(\mathrm{t}, J=5.2 \mathrm{~Hz}, 2 \mathrm{H}), 3.88(\mathrm{t}, J=5.2 \mathrm{~Hz}, 2 \mathrm{H})$.

\subsubsection{N-[2-[2-[3-(4-Pyridyl)-1,2,4-oxadiazol-5-yl]phenoxy]ethyl]cyclopentanamine (13)}

To a solution of $7(0.200 \mathrm{~g}, 0.578 \mathrm{mmol}, 1 \mathrm{eq})$ in DMF $(2 \mathrm{~mL})$ were added $\mathrm{K}_{2} \mathrm{CO}_{3}$ ( $0.160 \mathrm{~g}, 1.16 \mathrm{mmol}, 2 \mathrm{eq})$ and cyclopentanamine $(0.074 \mathrm{~g}, 0.867 \mathrm{mmol}, 1.5 \mathrm{eq})$. The reaction mixture was heated at $80{ }^{\circ} \mathrm{C}$ for $2 \mathrm{~h}$. After cooling to room temperature, the reaction mixture was diluted with water and extracted with $10 \% \mathrm{MeOH}$ in $\mathrm{CH}_{2} \mathrm{Cl}_{2}$. The organic phase was washed with brine, dried over $\mathrm{Na}_{2} \mathrm{SO}_{4}$, filtered and concentrated under reduced pressure. The residue was purified by reversed-phase HPLC (Xbridge C18 column, $250 \times 19 \mathrm{~mm}, 10 \mu ; 20$ to $65 \% \mathrm{ACN}$ in $20 \mathrm{mM}$ ammonium bicarbonate in $35 \mathrm{~min}$ ) to afford $0.040 \mathrm{~g}(20 \%)$ of the title compound as an off-white solid. LC-MS (ESI, $\mathrm{m} / z$ ): 
$351[\mathrm{M}+\mathrm{H}]^{+} . \quad{ }^{1} \mathrm{H}$ NMR $\left(400 \mathrm{MHz}, \mathrm{DMSO}-\mathrm{d}_{6}\right) \delta 8.84(\mathrm{~d}, J=4.9 \mathrm{~Hz}, 2 \mathrm{H}), 8.10$ $(\mathrm{d}, J=7.3 \mathrm{~Hz}, 1 \mathrm{H}), 8.00(\mathrm{~d}, J=4.9 \mathrm{~Hz}, 2 \mathrm{H}), 7.69(\mathrm{t}, J=7.8 \mathrm{~Hz}, 1 \mathrm{H}), 7.33(\mathrm{~d}, J=7.8 \mathrm{~Hz}$, $1 \mathrm{H}), 7.19(\mathrm{t}, J=7.3 \mathrm{~Hz}, 1 \mathrm{H}), 4.23(\mathrm{~m}, 2 \mathrm{H}), 3.09(\mathrm{~m}, 1 \mathrm{H}), 2.94(\mathrm{~m}, 2 \mathrm{H}), 1.70(\mathrm{~m}, 2 \mathrm{H}), 1.58$ $(\mathrm{m}, 2 \mathrm{H}), 1.44(\mathrm{~m}, 2 \mathrm{H}), 1.28(\mathrm{~m}, 2 \mathrm{H})(\mathrm{NH}$ not visible) (Figure $\mathrm{S} 15) .{ }^{13} \mathrm{C}$ NMR $(150 \mathrm{MHz}$, DMSO- $\left.d_{6}\right) \delta 175.63,166.45,157.72,150.95,135.23,133.73,131.22,121.09,114.05,112.21$, $68.89,58.94,46.70,32.80,23.58$ (Figure S16).

3.1.13. N-Methyl-N-[2-[2-[3-(4-pyridyl)-1,2,4-oxadiazol-5-yl]phenoxy]ethyl]cyclopentanamine (14)

The title compound was prepared similarly to 13 using $N$-methylcyclopentanamine instead of cyclopentanamine. LC-MS (ESI, $m / z): 365[\mathrm{M}+\mathrm{H}]^{+} .{ }^{1} \mathrm{H} \mathrm{NMR}(400 \mathrm{MHz}$, DMSO- $\left.d_{6}\right) \delta 8.84(\mathrm{~d}, J=5.9 \mathrm{~Hz}, 2 \mathrm{H}), 8.08(\mathrm{~d}, J=7.3 \mathrm{~Hz}, 1 \mathrm{H}), 8.01(\mathrm{~d}, J=5.9 \mathrm{~Hz}, 2 \mathrm{H})$, $7.69(\mathrm{t}, J=7.8 \mathrm{~Hz}, 1 \mathrm{H}), 7.35(\mathrm{~d}, J=7.8 \mathrm{~Hz}, 1 \mathrm{H}), 7.18(\mathrm{t}, J=7.3 \mathrm{~Hz}, 1 \mathrm{H}), 4.24(\mathrm{~m}, 2 \mathrm{H}), 2.83$ $(\mathrm{m}, 2 \mathrm{H}), 2.75(\mathrm{~m}, 1 \mathrm{H}), 2.26(\mathrm{~s}, 3 \mathrm{H}), 1.71(\mathrm{~m}, 2 \mathrm{H}), 1.54(\mathrm{~m}, 2 \mathrm{H}), 1.43(\mathrm{~m}, 2 \mathrm{H}), 1.33(\mathrm{~m}, 2 \mathrm{H})$ (Figure S17). ${ }^{13} \mathrm{C}$ NMR $\left(150 \mathrm{MHz}, \mathrm{DMSO}-d_{6}\right) \delta 175.83,166.36,157.75,150.98,135.12,133.73$, 131.36, 121.08, 120.93, 113.94, 112.30, 67.65, 66.21, 53.98, 40.80, 29.92, 23.84 (Figure S18).

\subsubsection{4. tert-Butyl 3-(2-(methoxycarbonyl)phenoxy)pyrrolidine-1-carboxylate (17)}

To a solution of DIAD $(8.8 \mathrm{~mL}, 44.9 \mathrm{mmol}, 1.2 \mathrm{eq})$ in THF $(20 \mathrm{~mL})$ cooled at $0{ }^{\circ} \mathrm{C}$ was added $\mathrm{PPh}_{3}(10.5 \mathrm{~g}, 41.1 \mathrm{mmol}, 1.1 \mathrm{eq})$. The reaction mixture was stirred at $0{ }^{\circ} \mathrm{C}$ for $30 \mathrm{~min}$. tert-Butyl 3-hydroxypyrrolidine-1-carboxylate $(7.0 \mathrm{~g}, 37.4 \mathrm{mmol}, 1 \mathrm{eq})$ was added and the reaction mixture was stirred at $0{ }^{\circ} \mathrm{C}$ for $15 \mathrm{~min}$. Methyl 2-hydroxybenzoate $(5.7 \mathrm{~g}, 37.4 \mathrm{mmol}, 1 \mathrm{eq})$ was added and the reaction mixture was stirred at room temperature overnight. The reaction mixture was concentrated under reduced pressure. The residue was partitioned between water and EtOAc. The phases were separated. The aqueous phase was extracted twice with EtOAc. The organic phases were combined, dried over $\mathrm{Na}_{2} \mathrm{SO}_{4}$, filtered, and concentrated under reduced pressure. The residue was purified by flash chromatography on silica gel using a gradient of EtOAc (0-50\%) in hexane to afford $4.0 \mathrm{~g}(33 \%)$ of the title compound as a colorless liquid. ${ }^{1} \mathrm{H} \mathrm{NMR}\left(400 \mathrm{MHz}, \mathrm{CDCl}_{3}\right) \delta 7.77$ $(\mathrm{dd}, J=1.6,7.6 \mathrm{~Hz}, 1 \mathrm{H}), 7.42(\mathrm{~m}, 1 \mathrm{H}), 7.00(\mathrm{t}, J=7.6 \mathrm{~Hz}, 1 \mathrm{H}), 6.91(\mathrm{~d}, J=8.4 \mathrm{~Hz}, 1 \mathrm{H}), 4.94$ $(\mathrm{m}, 1 \mathrm{H}), 3.85(\mathrm{~s}, 3 \mathrm{H}), 3.52-3.60(\mathrm{~m}, 4 \mathrm{H}), 2.22(\mathrm{~m}, 1 \mathrm{H}), 2.07(\mathrm{~m}, 1 \mathrm{H}), 1.45(\mathrm{~s}, 9 \mathrm{H})$.

\subsubsection{Methyl 2-(pyrrolidin-3-yloxy)benzoate hydrochloride (18)}

To a solution of $17(12.8 \mathrm{~g}, 39.7 \mathrm{mmol}, 1 \mathrm{eq})$ in $\mathrm{CH}_{2} \mathrm{Cl}_{2}(130 \mathrm{~mL})$ cooled at $0{ }^{\circ} \mathrm{C}$ was added $4 \mathrm{~N} \mathrm{HCl}$ in dioxane $(30 \mathrm{~mL}, 120 \mathrm{mmol}, 3 \mathrm{eq})$. The reaction mixture was stirred at room temperature overnight and was concentrated under reduced pressure to afford quantitatively the title compound as a brown oil. ${ }^{1} \mathrm{H}$ NMR $\left(400 \mathrm{MHz}, \mathrm{DMSO}-d_{6}\right) \delta 9.56$ (br. s., 1H), 9.30 (br. s., $1 \mathrm{H}), 7.70$ (dd, $J=1.6,7.6 \mathrm{~Hz}, 1 \mathrm{H}), 7.56(\mathrm{t}, J=8.4 \mathrm{~Hz}, 1 \mathrm{H}), 7.23$ $(\mathrm{d}, J=8.4 \mathrm{~Hz}, 1 \mathrm{H}), 7.09(\mathrm{t}, J=7.6 \mathrm{~Hz}, 1 \mathrm{H}), 5.22(\mathrm{~m}, 1 \mathrm{H}), 3.81(\mathrm{~s}, 3 \mathrm{H}), 3.49(\mathrm{~m}, 1 \mathrm{H}), 3.15-3.40$ $(\mathrm{m}, 3 \mathrm{H}), 2.14(\mathrm{~m}, 2 \mathrm{H})$.

\subsubsection{Methyl 2-((1-cyclopentylpyrrolidin-3-yl)oxy)benzoate (19)}

To a solution of $18(11.4 \mathrm{~g}, 44.2 \mathrm{mmol}, 1 \mathrm{eq})$ in $\mathrm{CH}_{2} \mathrm{Cl}_{2}(120 \mathrm{~mL})$ was added cyclopentanone $(5.1 \mathrm{~mL}, 57.5 \mathrm{mmol}, 1.3 \mathrm{eq})$ and the reaction mixture was stirred at room temperature for $3 \mathrm{~h} . \mathrm{NaBH}(\mathrm{OAc})_{3}(14.1 \mathrm{~g}, 66.4 \mathrm{mmol}, 1.5 \mathrm{eq})$ was added portion-wise and the reaction mixture was stirred at room temperature overnight. The reaction mixture was washed with water and the phases were separated. The aqueous phase was extracted with $10 \% \mathrm{MeOH}$ in $\mathrm{CH}_{2} \mathrm{Cl}_{2}(3 \times)$. The organic phases were combined, dried over $\mathrm{Na}_{2} \mathrm{SO}_{4}$, filtered, and concentrated under reduced pressure. The residue was purified by flash chromatography on silica gel using a gradient of $\mathrm{MeOH}(0-10 \%)$ in $\mathrm{CH}_{2} \mathrm{Cl}_{2}$ to afford $9.9 \mathrm{~g}(77 \%)$ of the title compound as a brown oil. ${ }^{1} \mathrm{H} \mathrm{NMR}\left(400 \mathrm{MHz}, \mathrm{CDCl}_{3}\right) \delta 7.77(\mathrm{~d}, J=6.8 \mathrm{~Hz}, 1 \mathrm{H})$, $7.43(\mathrm{t}, J=7.2 \mathrm{~Hz}, 1 \mathrm{H}), 6.99(\mathrm{t}, J=7.6 \mathrm{~Hz}, 1 \mathrm{H}), 6.89(\mathrm{~d}, J=8.4 \mathrm{~Hz}, 1 \mathrm{H}), 5.00(\mathrm{~m}, 1 \mathrm{H})$, $3.85(\mathrm{~s}, 3 \mathrm{H}), 3.74(\mathrm{~m}, 1 \mathrm{H}), 3.29(\mathrm{~m}, 1 \mathrm{H}), 3.10(\mathrm{~m}, 1 \mathrm{H}), 2.92-3.02(\mathrm{~m}, 2 \mathrm{H}), 2.34(\mathrm{~m}, 1 \mathrm{H}), 2.15$ $(\mathrm{m}, 1 \mathrm{H}), 1.93(\mathrm{~m}, 3 \mathrm{H}), 1.76(\mathrm{~m}, 3 \mathrm{H}), 1.55(\mathrm{~m}, 2 \mathrm{H})$. 


\subsubsection{Lithium 2-((1-cyclopentylpyrrolidin-3-yl)oxy)benzoate (20)}

To a solution of $19(1.0 \mathrm{~g}, 3.46 \mathrm{mmol}, 1 \mathrm{eq})$ in THF $(30 \mathrm{~mL}), \mathrm{MeOH}(10 \mathrm{~mL})$ and water $(20 \mathrm{~mL})$ was added $\mathrm{LiOH}(0.138 \mathrm{~g}, 3.28 \mathrm{mmol}, 0.9 \mathrm{eq})$. The reaction mixture was heated at $60^{\circ} \mathrm{C}$ for $6 \mathrm{~h}$ and was concentrated under reduced pressure. The residue was dissolved in water $(30 \mathrm{~mL})$ and was washed twice with $\mathrm{CH}_{2} \mathrm{Cl}_{2}$. The aqueous phase was lyophilized to afford $0.800 \mathrm{~g}(82 \%)$ of lithium 2-((1-cyclopentylpyrrolidin-3-yl)oxy)benzoate as an offwhite solid. ${ }^{1} \mathrm{H}$ NMR $\left(400 \mathrm{MHz}, \mathrm{DMSO}-d_{6}\right) \delta 7.15(\mathrm{~d}, J=7.2 \mathrm{~Hz}, 1 \mathrm{H}), 7.04(\mathrm{t}, J=7.6 \mathrm{~Hz}$, $1 \mathrm{H}), 6.75(\mathrm{~m}, 2 \mathrm{H}), 4.75(\mathrm{~m}, 1 \mathrm{H}), 2.80(\mathrm{~m}, 1 \mathrm{H}), 2.57-2.66(\mathrm{~m}, 2 \mathrm{H}), 2.41(\mathrm{~m}, 2 \mathrm{H}), 2.13(\mathrm{~m}, 1 \mathrm{H})$, $1.70-1.85(\mathrm{~m}, 3 \mathrm{H}), 1.58-1.64(\mathrm{~m}, 2 \mathrm{H}), 1.30-1.55(\mathrm{~m}, 4 \mathrm{H})$.

\subsubsection{5-[2-(1-Cyclopentylpyrrolidin-3-yl)oxyphenyl]-3-(3-pyridyl)-1,2,4-oxadiazole (23)}

To a solution of $N$-hydroxynicotinimidamide $(0.150 \mathrm{~g}, 1.09 \mathrm{mmol}, 1 \mathrm{eq})$ in DMSO $(2 \mathrm{~mL})$ were added 19 (0.474 g, $1.64 \mathrm{mmol}, 1.5 \mathrm{eq})$ and $\mathrm{NaOH}(0.066 \mathrm{~g}, 1.64 \mathrm{mmol}, 1.5 \mathrm{eq})$. The reaction mixture was stirred at room temperature overnight. The reaction mixture was diluted with water and extracted with EtOAc. The organic phase was dried over $\mathrm{Na}_{2} \mathrm{SO}_{4}$, filtered, and concentrated under reduced pressure. The residue was purified by flash chromatography on silica gel using a gradient of $\mathrm{MeOH}(10-20 \%)$ in EtOAc. A second purification by reversed-phase HPLC (Xterra RP18 column, $250 \times 19 \mathrm{~mm}, 10 \mu ; 20$ to $85 \%$ $\mathrm{MeOH}$ in $20 \mathrm{mM}$ ammonium bicarbonate in $24 \mathrm{~min})$ furnished $0.015 \mathrm{~g}(4 \%)$ of the title compound as an off-white solid. LC-MS (ESI, $m / z): 377[\mathrm{M}+\mathrm{H}]^{+} .{ }^{1} \mathrm{H}$ NMR $(400 \mathrm{MHz}$, DMSO- $\left.d_{6}\right) \delta 9.26(\mathrm{~s}, 1 \mathrm{H}), 8.81(\mathrm{~d}, J=3.9 \mathrm{~Hz}, 1 \mathrm{H}), 8.44(\mathrm{~d}, J=7.3 \mathrm{~Hz}, 1 \mathrm{H}), 8.12(\mathrm{~d}, J=7.3 \mathrm{~Hz}$, $1 \mathrm{H}), 7.67(\mathrm{~m}, 2 \mathrm{H}), 7.09-7.38(\mathrm{~m}, 2 \mathrm{H}), 5.07(\mathrm{~m}, 1 \mathrm{H}), 3.01(\mathrm{~m}, 1 \mathrm{H}), 2.70(\mathrm{~m}, 2 \mathrm{H}), 2.33(\mathrm{~m}, 2 \mathrm{H})$, $1.89(\mathrm{~m}, 1 \mathrm{H}), 1.73(\mathrm{~m}, 2 \mathrm{H}), 1.60(\mathrm{~m}, 2 \mathrm{H}), 1.31-1.54(\mathrm{~m}, 5 \mathrm{H})$ (Figure S19).

\subsubsection{5-[2-(1-Cyclopentylpyrrolidin-3-yl)oxyphenyl]-3-pyrimidin-5-yl-1,2,4-oxadiazole (24)}

A mixture of $20(0.250 \mathrm{~g}, 0.889 \mathrm{mmol}, 1 \mathrm{eq})$, HATU $(0.406 \mathrm{~g}, 1.07 \mathrm{mmol}, 1.2 \mathrm{eq})$ and DIPEA (0.372 mL, $2.14 \mathrm{mmol}, 2.4 \mathrm{eq})$ in DMF $(3 \mathrm{~mL})$ was stirred at room temperature for $15 \mathrm{~min}$. After the addition of $\mathrm{N}$-hydroxypyrimidine-5-carboximidamide $(0.123 \mathrm{~g}$, $0.890 \mathrm{mmol}, 1 \mathrm{eq}$ ) [28], the reaction mixture was stirred at room temperature for $6 \mathrm{~h}$ and was heated at $100{ }^{\circ} \mathrm{C}$ overnight. After cooling to room temperature, the reaction mixture was diluted with $\mathrm{CH}_{2} \mathrm{Cl}_{2}$ and was washed with sat. $\mathrm{NaHCO}_{3}$. The phases were separated. The organic phase was washed with sat. $\mathrm{NaHCO}_{3}$, dried over $\mathrm{Na}_{2} \mathrm{SO}_{4}$, filtered, and concentrated under reduced pressure. The residue was purified by reversed-phase HPLC (YMC-Actus C18 column, $250 \times 20 \mathrm{~mm}, 5 \mu$; 40 to $90 \% \mathrm{ACN}$ in $20 \mathrm{mM}$ ammonium bicarbonate in $20 \mathrm{~min})$ to afford $0.050 \mathrm{~g}(15 \%)$ of the title compound as an off-white solid. LC-MS (ESI, $m / z): 378[\mathrm{M}+\mathrm{H}]^{+} .{ }^{1} \mathrm{H}$ NMR $\left(400 \mathrm{MHz}, \mathrm{CD}_{3} \mathrm{OD}\right) \delta 9.46(\mathrm{~s}, 2 \mathrm{H}), 9.33(\mathrm{~s}, 1 \mathrm{H})$, $8.16(\mathrm{dd}, J=1.5,7.8 \mathrm{~Hz}, 1 \mathrm{H}), 7.64(\mathrm{~m}, 1 \mathrm{H}), 7.10-7.24(\mathrm{~m}, 2 \mathrm{H}), 5.11(\mathrm{~m}, 1 \mathrm{H}), 3.16(\mathrm{~m}, 1 \mathrm{H})$, 2.84-3.04 (m, 2H), $2.69(\mathrm{~m}, 2 \mathrm{H}), 2.39(\mathrm{~m}, 1 \mathrm{H}), 2.13(\mathrm{~m}, 1 \mathrm{H}), 1.89(\mathrm{~m}, 2 \mathrm{H}), 1.71(\mathrm{~m}, 2 \mathrm{H})$, 1.39-1.64 (m, 4H) (Figure S20). ${ }^{13} \mathrm{C}$ NMR $(150 \mathrm{MHz}$, DMSO-d 6 ) $\delta 175.78,163.96,160.47$, $156.72,155.31,135.21,131.64,121.45,120.93,114.82,112.49,77.78,66.17,59.11,51.69,31.87$, $31.58,31.41,23.71$ (Figure S21).

\subsubsection{5-[2-(1-Cyclopentylpyrrolidin-3-yl)oxyphenyl]-3-pyridazin-4-yl-1,2,4-oxadiazole (25)}

A mixture of pyridazine-4-carbonitrile $(1.0 \mathrm{~g}, 9.52 \mathrm{mmol}, 1 \mathrm{eq})$, hydroxylamine hydrochloride (0.992 g, $14.3 \mathrm{mmol}, 1.5 \mathrm{eq})$ and DIPEA ( $3.3 \mathrm{~mL}, 19.0 \mathrm{mmol}, 2 \mathrm{eq})$ in $\mathrm{EtOH}$ $(40 \mathrm{~mL})$ was heated at $90{ }^{\circ} \mathrm{C}$ overnight. The reaction mixture was concentrated under reduced pressure. The residue was partitioned between EtOAc and water. The phases were separated. The organic phase was dried over $\mathrm{Na}_{2} \mathrm{SO}_{4}$, filtered, and concentrated under reduced pressure. The residue was purified by flash chromatography on silica gel using a gradient of THF $(0-70 \%)$ in hexane to afford $0.300 \mathrm{~g}(23 \%)$ of $N$-hydroxypyridazine4-carboximidamide as an off-white solid. LC-MS (ESI, $m / z)$ : $139[\mathrm{M}+\mathrm{H}]^{+} .{ }^{1} \mathrm{H}$ NMR $\left(400 \mathrm{MHz}, \mathrm{DMSO}-d_{6}\right) \delta 10.36(\mathrm{~s}, 1 \mathrm{H}), 9.45(\mathrm{~s}, 1 \mathrm{H}), 9.25(\mathrm{~d}, J=6.1 \mathrm{~Hz}, 1 \mathrm{H}), 7.86(\mathrm{~m}, 1 \mathrm{H}), 6.19$ (br. s., 2H). 
The title compound was prepared similarly to 24 using $N$-hydroxypyridazine-4carboximidamide instead of $N$-hydroxypyrimidine-5-carboximidamide. LC-MS (ESI, $m / z)$ : $378[\mathrm{M}+\mathrm{H}]^{+} .{ }^{1} \mathrm{H}$ NMR $\left(400 \mathrm{MHz}, \mathrm{DMSO}-d_{6}\right) \delta 9.81(\mathrm{~s}, 1 \mathrm{H}), 9.53(\mathrm{~d}, J=4.9 \mathrm{~Hz}, 1 \mathrm{H})$, $8.27(\mathrm{~d}, J=4.9 \mathrm{~Hz}, 1 \mathrm{H}), 8.14(\mathrm{~d}, J=7.8 \mathrm{~Hz}, 1 \mathrm{H}), 7.69(\mathrm{t}, J=7.8 \mathrm{~Hz}, 1 \mathrm{H}), 7.26(\mathrm{~d}, J=7.8 \mathrm{~Hz}$, $1 \mathrm{H}), 7.19(\mathrm{~m}, 1 \mathrm{H}), 5.08(\mathrm{~m}, 1 \mathrm{H}), 3.02(\mathrm{~m}, 1 \mathrm{H}), 2.70(\mathrm{~m}, 2 \mathrm{H}), 2.41-2.62(\mathrm{~m}, 2 \mathrm{H}), 2.33(\mathrm{~m}, 1 \mathrm{H})$, $1.90(\mathrm{~m}, 1 \mathrm{H}), 1.73(\mathrm{~m}, 2 \mathrm{H}), 1.61(\mathrm{~m}, 2 \mathrm{H}), 1.32-1.55(\mathrm{~m}, 4 \mathrm{H})$ (Figure S22). ${ }^{13} \mathrm{C}$ NMR $(150 \mathrm{MHz}$, DMSO- $\left.d_{6}\right) \delta 176.17,164.64,156.77,152.60,148.23,135.34,131.67,125.08,123.92,120.96$, $114.83,112.37,77.81,66.15,59.10,51.69,31.87,31.59,31.41,23.71$ (Figure S23).

\subsubsection{5-[2-(1-Cyclopentylpyrrolidin-3-yl)oxyphenyl]-3-phenyl-1,2,4-oxadiazole (26)}

The title compound was prepared similarly to 23 using $N$-hydroxybenzimidamide instead of $N$-hydroxynicotinimidamide. LC-MS (ESI, $m / z): 376[\mathrm{M}+\mathrm{H}]^{+}$. ${ }^{1} \mathrm{H}$ NMR $\left(400 \mathrm{MHz}, \mathrm{DMSO}-d_{6}\right) \delta 8.10(\mathrm{~m}, 3 \mathrm{H}), 7.51-7.80(\mathrm{~m}, 4 \mathrm{H}), 7.24(\mathrm{~d}, J=8.8 \mathrm{~Hz}, 1 \mathrm{H}), 7.17$ $(\mathrm{t}, J=7.6 \mathrm{~Hz}, 1 \mathrm{H}), 5.06(\mathrm{~m}, 1 \mathrm{H}), 3.01(\mathrm{~m}, 1 \mathrm{H}), 2.64-2.84(\mathrm{~m}, 2 \mathrm{H}), 2.43-2.55(\mathrm{~m}, 2 \mathrm{H}), 2.31$ $(\mathrm{m}, 1 \mathrm{H}), 1.89(\mathrm{~m}, 1 \mathrm{H}), 1.73(\mathrm{~m}, 2 \mathrm{H}), 1.60(\mathrm{~m}, 2 \mathrm{H}), 1.32-1.54(\mathrm{~m}, 4 \mathrm{H})$ (Figure S24). ${ }^{13} \mathrm{C}$ NMR $\left(150 \mathrm{MHz}, \mathrm{DMSO}-d_{6}\right) \delta 175.14,167.59,156.60,134.78,131.60,131.50,129.32,127.12,126.48$, $120.86,114.78,113.03,77.73,66.14,59.10,51.67,31.88,31.57,31.40,23.70$ (Figure S25).

\subsubsection{5-[2-(1-Cyclopentylpyrrolidin-3-yl)oxyphenyl]-3-(6-methoxy-3-pyridyl)-1,2,4-oxadiazole (27)}

A mixture of 6-methoxynicotinonitrile $(1.0 \mathrm{~g}, 7.45 \mathrm{mmol}, 1 \mathrm{eq})$, hydroxylamine hydrochloride $(0.777 \mathrm{~g}, 11.2 \mathrm{mmol}, 1.5 \mathrm{eq})$ and $\mathrm{K}_{2} \mathrm{CO}_{3}(3.09 \mathrm{~g}, 22.4 \mathrm{mmol}, 3 \mathrm{eq})$ in EtOH $(50 \mathrm{~mL})$ was heated at $80{ }^{\circ} \mathrm{C}$ overnight. The reaction mixture was concentrated under reduced pressure. The residue was partitioned between EtOAc and water. The phases were separated. The organic phase was dried over $\mathrm{Na}_{2} \mathrm{SO}_{4}$, filtered, and concentrated under reduced pressure. The residue was purified by flash chromatography on silica gel using a gradient of THF (0-40\%) in hexane to afford $0.200 \mathrm{~g}(16 \%)$ of N-hydroxy-6methoxynicotinimidamide as an off-white solid. LC-MS (ESI, $m / z): 168[\mathrm{M}+\mathrm{H}]^{+}$. ${ }^{1} \mathrm{H}$ NMR $\left(400 \mathrm{MHz}, \mathrm{DMSO}-d_{6}\right) \delta 9.62(\mathrm{~s}, 1 \mathrm{H}), 8.43(\mathrm{~s}, 1 \mathrm{H}), 7.93(\mathrm{~m}, 1 \mathrm{H}), 6.83(\mathrm{~d}, J=8.4 \mathrm{~Hz}, 1 \mathrm{H}), 5.86$ (br. s., 2H), 3.86 (s, 3H).

The title compound was prepared similarly to 24 using N-hydroxy-6methoxynicotinimidamide instead of $N$-hydroxypyrimidine-5-carboximidamide. LC-MS (ESI, $m / z): 407[\mathrm{M}+\mathrm{H}]^{+} .{ }^{1} \mathrm{H}$ NMR $\left(400 \mathrm{MHz}, \mathrm{DMSO}-d_{6}\right) \delta 8.88(\mathrm{~d}, J=2.0 \mathrm{~Hz}, 1 \mathrm{H}), 8.32$ $(\mathrm{dd}, J=2.0,8.5 \mathrm{~Hz}, 1 \mathrm{H}), 8.09(\mathrm{~d}, J=7.5 \mathrm{~Hz}, 1 \mathrm{H}), 7.66(\mathrm{t}, J=7.8 \mathrm{~Hz}, 1 \mathrm{H}), 7.24(\mathrm{~d}, J=7.8 \mathrm{~Hz}$, $1 \mathrm{H}), 7.17(\mathrm{t}, J=7.5 \mathrm{~Hz}, 1 \mathrm{H}), 7.04(\mathrm{~d}, J=8.5 \mathrm{~Hz}, 1 \mathrm{H}), 5.06(\mathrm{~m}, 1 \mathrm{H}), 3.96(\mathrm{~s}, 3 \mathrm{H}), 3.02(\mathrm{~m}, 1 \mathrm{H})$, $2.70(\mathrm{~m}, 2 \mathrm{H}), 2.41-2.62(\mathrm{~m}, 2 \mathrm{H}), 2.26-2.37(\mathrm{~m}, 1 \mathrm{H}), 1.88(\mathrm{~m}, 1 \mathrm{H}), 1.73(\mathrm{~m}, 2 \mathrm{H}), 1.61(\mathrm{~m}, 2 \mathrm{H})$, 1.33-1.55 (m, 4H) (Figure S26).

3.1.23. 5-[2-(1-Cyclopentylpyrrolidin-3-yl)oxyphenyl]-3-[5-(trifluoromethyl)-3-pyridyl]1,2,4-oxadiazole (28)

A mixture of 5-(trifluoromethyl)nicotinonitrile $(0.250 \mathrm{~g}, 1.45 \mathrm{mmol}, 1 \mathrm{eq})$, hydroxylamine hydrochloride $(0.151 \mathrm{~g}, 2.18 \mathrm{mmol}, 1.5 \mathrm{eq})$ and DIPEA $(0.600 \mathrm{~mL}, 3.6 \mathrm{mmol})$ in EtOH $(5 \mathrm{~mL})$ was heated at $90{ }^{\circ} \mathrm{C}$ overnight. The reaction mixture was concentrated under reduced pressure. The residue was partitioned between EtOAc and water. The phases were separated. The organic phase was dried over $\mathrm{Na}_{2} \mathrm{SO}_{4}$, filtered, and concentrated under reduced pressure. The residue was triturated with EtOAc. The white solid was filtered and dried under high vacuum to afford $0.250 \mathrm{~g}$ (83\%) of N-hydroxy-5(trifluoromethyl)nicotinimidamide. LC-MS (ESI, $m / z)$ : $206[\mathrm{M}+\mathrm{H}]^{+} .{ }^{1} \mathrm{H} \mathrm{NMR}(400 \mathrm{MHz}$, DMSO- $\left.d_{6}\right) \delta 10.09$ (s, 1H), 9.15 (s, 1H), 8.96 (s, 1H), 8.36 (s, 1H), 6.18 (br. s., 2H).

The title compound was prepared similarly to 24 using $N$-hydroxy-5-(trifluoromethyl) nicotinimidamide instead of $N$-hydroxypyrimidine-5-carboximidamide. LC-MS (ESI, $m / z)$ : $445[\mathrm{M}+\mathrm{H}]^{+} .{ }^{1} \mathrm{H}$ NMR $\left(400 \mathrm{MHz}, \mathrm{DMSO}-d_{6}\right) \delta 9.53(\mathrm{~s}, 1 \mathrm{H}), 9.25(\mathrm{~s}, 1 \mathrm{H}), 8.70(\mathrm{~s}, 1 \mathrm{H}), 8.15$ $(\mathrm{d}, J=7.3 \mathrm{~Hz}, 1 \mathrm{H}), 7.68(\mathrm{t}, J=7.8 \mathrm{~Hz}, 1 \mathrm{H}), 7.26(\mathrm{~d}, J=7.8 \mathrm{~Hz}, 1 \mathrm{H}), 7.19(\mathrm{t}, J=7.3 \mathrm{~Hz}, 1 \mathrm{H})$, $5.08(\mathrm{~m}, 1 \mathrm{H}), 3.03(\mathrm{~m}, 1 \mathrm{H}), 2.65-2.77(\mathrm{~m}, 2 \mathrm{H}), 2.41-2.62(\mathrm{~m}, 2 \mathrm{H}), 2.33(\mathrm{~m}, 1 \mathrm{H}), 1.89(\mathrm{~m}, 1 \mathrm{H})$, $1.73(\mathrm{~m}, 2 \mathrm{H}), 1.60(\mathrm{~m}, 2 \mathrm{H}), 1.31-1.55(\mathrm{~m}, 4 \mathrm{H})$ (Figure S27). ${ }^{13} \mathrm{C}$ NMR $\left(150 \mathrm{MHz}, \mathrm{DMSO}-d_{6}\right) \delta$ 
$175.76,164.91,156.73,151.54,148.85,135.23,131.75,131.65,123.17,120.93,114.83,112.47$, $77.79,66.19,59.14,51.70,31.89,31.58,31.41,23.69$ (Figure S28).

3.1.24. 5-[2-(1-Cyclopentylpyrrolidin-3-yl)oxyphenyl]-3-[4-(trifluoromethyl)-3-pyridyl]1,2,4-oxadiazole (29)

A mixture of 4-(trifluoromethyl)nicotinonitrile $(0.250 \mathrm{~g}, 1.45 \mathrm{mmol}, 1 \mathrm{eq})$, hydroxylamine hydrochloride $(0.151 \mathrm{~g}, 2.18 \mathrm{mmol}, 1.5 \mathrm{eq})$ and DIPEA $(0.506 \mathrm{~mL}, 2.91 \mathrm{mmol}, 2 \mathrm{eq})$ in $\mathrm{EtOH}(10 \mathrm{~mL})$ was heated at $90{ }^{\circ} \mathrm{C}$ overnight. The reaction mixture was concentrated under reduced pressure. The residue was partitioned between EtOAc and water. The phases were separated. The organic phase was dried over $\mathrm{Na}_{2} \mathrm{SO}_{4}$, filtered, and concentrated under reduced pressure. The residue was purified by flash chromatography on silica gel using a gradient of THF (0-30\%) in hexane to afford $0.140 \mathrm{~g}$ (47\%) of N-hydroxy-4(trifluoromethyl)nicotinimidamide as an off-white solid. LC-MS (ESI, $m / z): 206[\mathrm{M}+\mathrm{H}]^{+}$. ${ }^{1} \mathrm{H}$ NMR (400 MHz, DMSO-d 6 ) $\delta 9.76$ (s, 1H), 8.85 (d, J = 4.9 Hz, 1H), 8.75 (s, 1H), 7.78 (d, $J=4.9 \mathrm{~Hz}, 1 \mathrm{H}), 6.04$ (br. s., $2 \mathrm{H}$ ).

The title compound was prepared similarly to 24 using $N$-hydroxy-4-(trifluoromethyl) nicotinimidamide instead of $N$-hydroxypyrimidine-5-carboximidamide. LC-MS (ESI, $m / z)$ : $445[\mathrm{M}+\mathrm{H}]^{+} .{ }^{1} \mathrm{H}$ NMR $\left(400 \mathrm{MHz}, \mathrm{DMSO}-d_{6}\right) \delta 9.22(\mathrm{~s}, 1 \mathrm{H}), 9.11(\mathrm{~d}, J=4.5 \mathrm{~Hz}, 1 \mathrm{H})$, $8.06(\mathrm{~m}, 2 \mathrm{H}), 7.68(\mathrm{t}, J=7.3 \mathrm{~Hz}, 1 \mathrm{H}), 7.26(\mathrm{~d}, J=8.3 \mathrm{~Hz}, 1 \mathrm{H}), 7.18(\mathrm{t}, J=7.3 \mathrm{~Hz}, 1 \mathrm{H}), 5.08$ $(\mathrm{m}, 1 \mathrm{H}), 3.03(\mathrm{~m}, 1 \mathrm{H}), 2.70(\mathrm{~m}, 2 \mathrm{H}), 2.41-2.62(\mathrm{~m}, 2 \mathrm{H}), 2.33(\mathrm{~m}, 1 \mathrm{H}), 1.89(\mathrm{~m}, 1 \mathrm{H}), 1.72$ $(\mathrm{m}, 2 \mathrm{H}), 1.60(\mathrm{~m}, 2 \mathrm{H}), 1.30-1.54(\mathrm{~m}, 4 \mathrm{H})$ (Figure S29). ${ }^{13} \mathrm{C}$ NMR $\left(150 \mathrm{MHz}, \mathrm{DMSO}-d_{6}\right) \delta$ $175.38,164.73$, 156.73, 153.66, 151.87, 135.23, 131.57, 125.08, 120.94, 120.73, 120.70, 119.84, $114.79,112.34,77.75,66.12,59.02,51.65,31.82,31.52,31.37,23.67$ (Figure S30).

\subsubsection{5-[2-(1-Cyclopentylpyrrolidin-3-yl)oxyphenyl]-3-(4-methyl-3-pyridyl)-1,2,4-oxadiazole (30)}

A mixture of 4-methylnicotinonitrile $(0.500 \mathrm{~g}, 4.23 \mathrm{mmol}, 1 \mathrm{eq})$, hydroxylamine hydrochloride $(0.441 \mathrm{~g}, 6.35 \mathrm{mmol}, 1.5 \mathrm{eq})$ and $\mathrm{NEt}_{3}(1.2 \mathrm{~mL}, 8.47 \mathrm{mmol}, 2 \mathrm{eq})$ in EtOH $(10 \mathrm{~mL})$ was stirred at room temperature overnight. The reaction mixture was concentrated under reduced pressure. The residue was purified by flash chromatography on silica gel using a gradient of THF (0-40\%) in hexane to afford $0.375 \mathrm{~g}(58 \%)$ of $N$-hydroxy-4methylnicotinimidamide as an off-white solid. LC-MS (ESI, $m / z): 152[\mathrm{M}+\mathrm{H}]^{+}$. ${ }^{1} \mathrm{H}$ NMR $\left(400 \mathrm{MHz}, \mathrm{DMSO}-d_{6}\right) \delta 9.52(\mathrm{~s}, 1 \mathrm{H}), 8.41(\mathrm{~m}, 2 \mathrm{H}), 7.26(\mathrm{~d}, J=5.0 \mathrm{~Hz}, 1 \mathrm{H}), 5.89$ (br. s., 2H), $2.36(\mathrm{~s}, 3 \mathrm{H})$.

The title compound was prepared similarly to 24 using $N$-hydroxy-4-methylnicotinimidamide instead of $N$-hydroxypyrimidine-5-carboximidamide. LC-MS (ESI, $m / z): 391[\mathrm{M}+\mathrm{H}]^{+}$. ${ }^{1} \mathrm{H}$ NMR (400 MHz, DMSO-d $) \delta 9.11(\mathrm{~s}, 1 \mathrm{H}), 8.62(\mathrm{~d}, J=5.4 \mathrm{~Hz}, 1 \mathrm{H}), 8.11(\mathrm{~d}, J=7.8 \mathrm{~Hz}, 1 \mathrm{H})$, $7.66(\mathrm{t}, J=8.3 \mathrm{~Hz}, 1 \mathrm{H}), 7.49(\mathrm{~d}, J=5.4 \mathrm{~Hz}, 1 \mathrm{H}), 7.25(\mathrm{~d}, J=8.3 \mathrm{~Hz}, 1 \mathrm{H}), 7.17(\mathrm{t}, J=7.8 \mathrm{~Hz}, 1 \mathrm{H}), 5.07$ $(\mathrm{m}, 1 \mathrm{H}), 3.02(\mathrm{~m}, 1 \mathrm{H}), 2.71(\mathrm{~m}, 2 \mathrm{H}), 2.65(\mathrm{~s}, 3 \mathrm{H}), 2.41-2.62(\mathrm{~m}, 2 \mathrm{H}), 2.33(\mathrm{~m}, 1 \mathrm{H}), 1.89(\mathrm{~m}, 1 \mathrm{H}), 1.72$ $(\mathrm{m}, 2 \mathrm{H}), 1.60(\mathrm{~m}, 2 \mathrm{H}), 1.31-1.54(\mathrm{~m}, 4 \mathrm{H})$ (Figure S31). ${ }^{13} \mathrm{C}$ NMR (150 MHz, DMSO-d 6 ) $\delta 174.44$, $166.42,156.62,151.34,149.79,146.79,134.91,131.59,126.30,122.42,120.87,120.70,114.74,112.73$, 77.68, 66.16, 59.10, 51.70, 31.87, 31.56, 31.41, 23.69, 20.99 (Figure S32).

3.1.26. 5-[2-(1-Cyclopentylpyrrolidin-3-yl)oxyphenyl]-3-(3-methyl-4-pyridyl)-1,2,4oxadiazole (31)

A mixture of 3-methylisonicotinonitrile $(0.250 \mathrm{~g}, 2.11 \mathrm{mmol}, 1 \mathrm{eq})$, hydroxylamine hydrochloride $(0.294 \mathrm{~g}, 4.24 \mathrm{mmol}, 2 \mathrm{eq})$ and $\mathrm{NaHCO}_{3}(0.712 \mathrm{~g}, 8.48 \mathrm{mmol}, 4 \mathrm{eq})$ in $\mathrm{MeOH}$ $(5 \mathrm{~mL})$ was heated at $70^{\circ} \mathrm{C}$ for $6 \mathrm{~h}$. The reaction mixture was concentrated under reduced pressure. The residue was purified by reversed-phase HPLC (YMC-Actus C18 column, $250 \times 20 \mathrm{~mm}, 5 \mu ; 5 \% \mathrm{MeOH}$ in $20 \mathrm{mM}$ ammonium bicarbonate) to afford $0.180 \mathrm{~g} \mathrm{(56 \% )}$ of $N$-hydroxy-3-methylisonicotinimidamide as an off-white solid. LC-MS (ESI, $m / z)$; $152[\mathrm{M}+\mathrm{H}]^{+} .{ }^{1} \mathrm{H}$ NMR $\left(400 \mathrm{MHz}, \mathrm{DMSO}-d_{6}\right) \delta 9.65(\mathrm{~s}, 1 \mathrm{H}), 8.47(\mathrm{~s}, 1 \mathrm{H}), 8.40$ $(\mathrm{d}, J=4.8 \mathrm{~Hz}, 1 \mathrm{H}), 7.29(\mathrm{~d}, J=4.8 \mathrm{~Hz}, 1 \mathrm{H}), 5.88$ (br. s., $2 \mathrm{H}), 2.35$ (s, 3H).

The title compound was prepared similarly to 24 using N-hydroxy-3methylisonicotinimidamide instead of $N$-hydroxypyrimidine-5-carboximidamide. LC-MS (ESI, $m / z): 391[\mathrm{M}+\mathrm{H}]^{+} .{ }^{1} \mathrm{H}$ NMR (400 MHz, DMSO-d 6$) \delta 8.70$ (s, 1H), 8.64 
$(\mathrm{d}, J=5.0 \mathrm{~Hz}, 1 \mathrm{H}), 8.11(\mathrm{~d}, J=7.5 \mathrm{~Hz}, 1 \mathrm{H}), 7.96(\mathrm{~d}, J=5.0 \mathrm{~Hz}, 1 \mathrm{H}), 7.67(\mathrm{t}, J=7.8 \mathrm{~Hz}$, $1 \mathrm{H}), 7.26(\mathrm{~d}, J=7.5 \mathrm{~Hz}, 1 \mathrm{H}), 7.18(\mathrm{t}, J=7.5 \mathrm{~Hz}, 1 \mathrm{H}), 5.08(\mathrm{~m}, 1 \mathrm{H}), 3.03(\mathrm{~m}, 1 \mathrm{H}), 2.71$ $(\mathrm{m}, 2 \mathrm{H}), 2.63(\mathrm{~s}, 3 \mathrm{H}), 2.41-2.62(\mathrm{~m}, 2 \mathrm{H}), 2.33(\mathrm{~m}, 1 \mathrm{H}), 1.90(\mathrm{~m}, 1 \mathrm{H}), 1.74(\mathrm{~m}, 2 \mathrm{H}), 1.61$ $(\mathrm{m}, 2 \mathrm{H}), 1.31-1.55(\mathrm{~m}, 4 \mathrm{H})$ (Figure S33). ${ }^{13} \mathrm{C}$ NMR $\left(150 \mathrm{MHz}, \mathrm{DMSO}-d_{6}\right) \delta 174.72,166.87$, $156.62,152.39,147.93,135.03,132.86,131.85,131.60,122.75,120.93,114.78,112.63,77.66$, $66.15,59.04,51.69,31.83,31.50,31.34,23.69,18.49$ (Figure S34).

\subsubsection{2-((1-Cyclopentylpyrrolidin-3-yl)oxy)benzonitrile (33)}

To a solution of 19 (1.6 g, $5.53 \mathrm{mmol}, 1 \mathrm{eq})$ in dioxane $(5 \mathrm{~mL})$ was added $25 \% \mathrm{NH}_{4} \mathrm{OH}$ (10 mL; $79.3 \mathrm{mmol}, 14 \mathrm{eq})$. The reaction mixture was heated at $100{ }^{\circ} \mathrm{C}$ overnight. The reaction mixture was concentrated under reduced pressure. The residue was partitioned between $10 \% \mathrm{LiOH}$ and $10 \% \mathrm{MeOH}$ in $\mathrm{CH}_{2} \mathrm{Cl}_{2}$. The phases were separated. The aqueous phase was extracted with $10 \% \mathrm{MeOH}$ in $\mathrm{CH}_{2} \mathrm{Cl}_{2}$. The organic phases were combined, dried over $\mathrm{Na}_{2} \mathrm{SO}_{4}$, filtered, and concentrated under reduced pressure to afford $0.900 \mathrm{~g}$ of 2-((1-cyclopentylpyrrolidin-3-yl)oxy)benzamide 32, which was used in the next step without further purification.

To a solution of $32(0.900 \mathrm{~g}, 3.28 \mathrm{mmol})$ in EtOAc $(20 \mathrm{~mL})$ was added $50 \%$ T3P in EtOAc $(4.8 \mathrm{~mL}, 16.4 \mathrm{mmol}, 5 \mathrm{eq})$. The reaction mixture was heated at $60^{\circ} \mathrm{C}$ overnight. The reaction mixture was concentrated under reduced pressure. The residue was partitioned between water and $10 \% \mathrm{MeOH}$ in $\mathrm{CH}_{2} \mathrm{Cl}_{2}$. The phases were separated. The aqueous phase was extracted twice with $10 \% \mathrm{MeOH}$ in $\mathrm{CH}_{2} \mathrm{Cl}_{2}$. The organic phases were combined, dried over $\mathrm{Na}_{2} \mathrm{SO}_{4}$, filtered, and concentrated under reduced pressure. The residue was purified by flash chromatography on silica gel using a gradient of $\mathrm{MeOH}(0-5 \%)$ in $\mathrm{CH}_{2} \mathrm{Cl}_{2}$ to afford $0.800 \mathrm{~g}$ ( $54 \%$ over two steps) of the title compound as a brown oil. LC-MS (ESI, $m / z$ ): $257[\mathrm{M}+\mathrm{H}]^{+}$.

3.1.28. 3-[2-(1-Cyclopentylpyrrolidin-3-yl)oxyphenyl]-5-(4-pyridyl)-1,2,4-oxadiazole (35)

A mixture of 2-((1-cyclopentylpyrrolidin-3-yl)oxy)benzonitrile $(0.700 \mathrm{~g}, 2.73 \mathrm{mmol}$, $1 \mathrm{eq})$, hydroxylamine hydrochloride $(0.569 \mathrm{~g}, 8.19 \mathrm{mmol}, 3 \mathrm{eq})$ and DIPEA $(1.9 \mathrm{~mL}$, $10.9 \mathrm{mmol}, 4 \mathrm{eq})$ in $\mathrm{EtOH}(10 \mathrm{~mL})$ was heated at $70{ }^{\circ} \mathrm{C}$ overnight. After cooling to room temperature, the reaction mixture was diluted with water and extracted with $10 \% \mathrm{MeOH}$ in $\mathrm{CH}_{2} \mathrm{Cl}_{2}(3 \times)$. The organic phases were combined, dried over $\mathrm{Na}_{2} \mathrm{SO}_{4}$, filtered, and concentrated under reduced pressure to afford $0.700 \mathrm{~g}(89 \%)$ of 2-((1-cyclopentylpyrrolidin3-yl)oxy)- $\mathrm{N}$-hydroxybenzimidamide 34 as an off-white solid, which was used in the next step without further purification. LC-MS (ESI, $m / z)$ : 290.

To a solution of $34(0.700 \mathrm{~g}, 2.42 \mathrm{mmol}, 1 \mathrm{eq})$ in DMF $(10 \mathrm{~mL})$ were added isonicotinic acid $(0.596 \mathrm{~g}, 4.84 \mathrm{mmol}, 2 \mathrm{eq}), \mathrm{EDC} . \mathrm{HCl}(0.927 \mathrm{~g}, 4.84 \mathrm{mmol}, 2 \mathrm{eq}), \mathrm{HOBt}(0.654 \mathrm{~g}$, $4.84 \mathrm{mmol}, 2 \mathrm{eq})$ and DIPEA $(1.7 \mathrm{~mL}, 9.68 \mathrm{mmol}, 4 \mathrm{eq})$. The reaction mixture was stirred at room temperature for $16 \mathrm{~h}$ and was heated at $80{ }^{\circ} \mathrm{C}$ for $16 \mathrm{~h}$. After cooling to room temperature, the reaction mixture was partitioned between water and EtOAc. The phases were separated. The organic phase was washed with brine, dried over $\mathrm{Na}_{2} \mathrm{SO}_{4}$, filtered and concentrated under reduced pressure. The residue was purified by reversed-phase HPLC (Xbridge C18 column, $250 \times 19 \mathrm{~mm}, 10 \mu ; 30$ to $75 \%$ ACN in $20 \mathrm{mM}$ ammonium bicarbonate in $22 \mathrm{~min}$ ) to afford $0.080 \mathrm{~g} \mathrm{(9 \% )}$ of the title compound as a white solid. LC-MS (ESI, $m / z): 377[\mathrm{M}+\mathrm{H}]^{+} .{ }^{1} \mathrm{H}$ NMR $\left(400 \mathrm{MHz}, \mathrm{DMSO}-d_{6}\right) \delta 8.91(\mathrm{~d}, J=5.9 \mathrm{~Hz}, 2 \mathrm{H}), 8.10$ $(\mathrm{d}, J=5.9 \mathrm{~Hz}, 2 \mathrm{H}), 7.98(\mathrm{~d}, J=7.4 \mathrm{~Hz}, 1 \mathrm{H}), 7.57(\mathrm{t}, J=7.1 \mathrm{~Hz}, 1 \mathrm{H}), 7.15(\mathrm{~m}, 2 \mathrm{H}), 5.01(\mathrm{~m}, 1 \mathrm{H})$, $3.02(\mathrm{~m}, 1 \mathrm{H}), 2.65(\mathrm{~m}, 2 \mathrm{H}), 2.42-2.55(\mathrm{~m}, 2 \mathrm{H}), 2.27(\mathrm{~m}, 1 \mathrm{H}), 1.86(\mathrm{~m}, 1 \mathrm{H}), 1.70(\mathrm{~m}, 2 \mathrm{H}), 1.59$ $(\mathrm{m}, 2 \mathrm{H}), 1.29-1.53(\mathrm{~m}, 4 \mathrm{H})$ (Figure S35). ${ }^{13} \mathrm{C}$ NMR (150 MHz, DMSO-d $\left.d_{6}\right) \delta 172.53,167.26$, $156.23,151.25,132.99,131.10,130.54,121.35,120.62$, 115.40, 114.33, 77.46, 66.15, 59.07, 51.65, 31.85, 31.55, 31.40, 23.69 (Figure S36).

\subsubsection{2-[2-(1-Cyclopentylpyrrolidin-3-yl)oxyphenyl]-5-(4-pyridyl)-1,3,4-oxadiazole (38)}

To a solution of $36(0.150 \mathrm{~g}, 0.545 \mathrm{mmol}, 1 \mathrm{eq})$ in $\mathrm{POCl}_{3}(5 \mathrm{~mL})$ was added isonicotinohydrazide $(0.075 \mathrm{~g}, 0.545 \mathrm{mmol}, 1 \mathrm{eq})$. The reaction mixture was heated at $90{ }^{\circ} \mathrm{C}$ overnight. 
The reaction mixture was concentrated under reduced pressure. The residue was taken up with sat. $\mathrm{NaHCO}_{3}$ and was extracted twice with $5 \% \mathrm{MeOH}$ in $\mathrm{CH}_{2} \mathrm{Cl}_{2}$. The organic phases were combined, washed with brine, dried over $\mathrm{Na}_{2} \mathrm{SO}_{4}$, filtered, and concentrated under reduced pressure. The residue was purified by reversed-phase HPLC (YMC-Actus C18 column, $250 \times 20 \mathrm{~mm}, 5 \mu ; 30$ to $75 \% \mathrm{ACN}$ in $20 \mathrm{mM}$ ammonium bicarbonate in $20 \mathrm{~min}$ ) to afford $0.040 \mathrm{~g}(19 \%)$ of the title compound as yellow solid. LC-MS (ESI, $m / z): 377[\mathrm{M}+\mathrm{H}]^{+}$. ${ }^{1} \mathrm{H}$ NMR (400 MHz, DMSO-d 6 ) $\delta 8.85(\mathrm{~m}, 2 \mathrm{H}), 8.01(\mathrm{~m}, 3 \mathrm{H}), 7.62(\mathrm{t}, J=7.3 \mathrm{~Hz}, 1 \mathrm{H}), 7.24$ $(\mathrm{d}, J=8.3 \mathrm{~Hz}, 1 \mathrm{H}), 7.16(\mathrm{t}, J=7.3 \mathrm{~Hz}, 1 \mathrm{H}), 5.07(\mathrm{~m}, 1 \mathrm{H}), 2.91(\mathrm{~m}, 1 \mathrm{H}), 2.79(\mathrm{~m}, 2 \mathrm{H}), 2.41-2.62$ $(\mathrm{m}, 2 \mathrm{H}), 2.34(\mathrm{~m}, 1 \mathrm{H}), 1.88(\mathrm{~m}, 1 \mathrm{H}), 1.72(\mathrm{~m}, 2 \mathrm{H}), 1.28-1.65(\mathrm{~m}, 6 \mathrm{H})$ (Figure S37). ${ }^{13} \mathrm{C}$ NMR $\left(150 \mathrm{MHz}, \mathrm{DMSO}-d_{6}\right) \delta$ 164.10, 162.43, 155.82, 151.02, 133.97, 130.70, 130.55, 120.87, 120.12, 114.65, 112.52, 77.58, 66.24, 59.31, 51.83, 31.91, 31.60, 31.40, 23.67 (Figure S38).

\subsubsection{3-Bromo-5-(2-methoxyphenyl)-1,2,4-thiadiazole (41)}

A mixture of 3-bromo-5-chloro-1,2,4-thiadiazole (1.0 g, $5.01 \mathrm{mmol}, 1 \mathrm{eq})$, (2-methoxyphenyl) boronic acid $(0.381 \mathrm{~g}, 2.51 \mathrm{mmol}, 0.5 \mathrm{eq})$ and $\mathrm{CsF}(1.52 \mathrm{~g}, 10.0 \mathrm{mmol}, 2 \mathrm{eq})$ in dioxane $(20 \mathrm{~mL})$ and water $(5 \mathrm{~mL})$ was degassed with Ar for $30 \mathrm{~min}$. $\mathrm{Pd}(\mathrm{dppf}) \mathrm{Cl}_{2}(0.367 \mathrm{~g}, 0.501 \mathrm{mmol}, 0.1 \mathrm{eq})$ was added and the reaction mixture was heated at $85{ }^{\circ} \mathrm{C}$ overnight. After cooling to room temperature, the reaction mixture was diluted with EtOAc and filtered. The phases of the filtrate were separated. The organic phase was concentrated under reduced pressure. The residue was purified by flash chromatography on silica gel using a gradient of EtOAc (0-20\%) in hexane to afford $0.620 \mathrm{~g}(46 \%)$ of the title compound as a white solid. ${ }^{1} \mathrm{H}$ NMR $\left(400 \mathrm{MHz}, \mathrm{DMSO}-d_{6}\right) \delta$ $8.24(\mathrm{~d}, J=6.6 \mathrm{~Hz}, 1 \mathrm{H}), 7.69(\mathrm{t}, J=7.2 \mathrm{~Hz}, 1 \mathrm{H}), 7.39(\mathrm{~d}, J=8.4 \mathrm{~Hz}, 1 \mathrm{H}), 7.22(\mathrm{t}, J=7.6 \mathrm{~Hz}, 1 \mathrm{H})$, $4.13(\mathrm{~s}, 3 \mathrm{H})$.

\subsubsection{5-(2-Methoxyphenyl)-3-(pyridin-4-yl)-1,2,4-thiadiazole (42)}

A mixture of 41 (0.550 g, $2.03 \mathrm{mmol}, 1 \mathrm{eq})$, pyridin-4-ylboronic acid (0.374 g, $3.04 \mathrm{mmol}, 1.5 \mathrm{eq})$ and $\mathrm{K}_{2} \mathrm{CO}_{3}(0.841 \mathrm{~g}, 6.09 \mathrm{mmol}, 3 \mathrm{eq})$ in dioxane $(20 \mathrm{~mL})$ and water $(5 \mathrm{~mL})$ was degassed with Ar for $30 \mathrm{~min}$. $\mathrm{Pd}(\mathrm{dppf}) \mathrm{Cl}_{2}(0.149 \mathrm{~g}, 0.203 \mathrm{mmol}, 0.1 \mathrm{eq})$ was added and the reaction mixture was heated at $85{ }^{\circ} \mathrm{C}$ for $16 \mathrm{~h}$. After cooling to room temperature, the reaction mixture was diluted with EtOAc and filtered. The phases of the filtrate were separated. The organic phase was concentrated under reduced pressure. The residue was purified by flash chromatography on silica gel using a gradient of EtOAc $(0-40 \%)$ in hexane to afford $0.450 \mathrm{~g}(83 \%)$ of the title compound as a white solid. LCMS (ESI, $m / z): 270[\mathrm{M}+\mathrm{H}]^{+} .{ }^{1} \mathrm{H}$ NMR $\left(400 \mathrm{MHz}, \mathrm{DMSO}-d_{6}\right) \delta 8.79(\mathrm{~d}, J=5.9 \mathrm{~Hz}, 2 \mathrm{H})$, $8.47(\mathrm{dd}, J=1.4,7.8 \mathrm{~Hz}, 1 \mathrm{H}), 8.21(\mathrm{~d}, J=6.0 \mathrm{~Hz}, 2 \mathrm{H}), 7.68(\mathrm{~m}, 1 \mathrm{H}), 7.40(\mathrm{~d}, J=8.2 \mathrm{~Hz}, 1 \mathrm{H})$, $7.26(\mathrm{t}, J=7.5 \mathrm{~Hz}, 1 \mathrm{H}), 4.16(\mathrm{~s}, 3 \mathrm{H})$.

\subsubsection{2. (3-(Pyridin-4-yl)-1,2,4-thiadiazol-5-yl)phenol (43)}

To a solution of $42(0.350 \mathrm{~g}, 1.30 \mathrm{mmol}, 1 \mathrm{eq})$ in NMP $(8 \mathrm{~mL})$ were added LiBr $(1.13 \mathrm{~g}$, $13.0 \mathrm{mmol}, 10 \mathrm{eq})$ and $p \mathrm{TsOH}(1.12 \mathrm{~g}, 6.50 \mathrm{mmol}, 5 \mathrm{eq})$. The reaction mixture was heated at $150{ }^{\circ} \mathrm{C}$ for $1.5 \mathrm{~h}$. After cooling to room temperature, the reaction mixture was diluted with water and extracted with EtOAc $(3 \times)$. The organic phases were combined, washed with brine, dried over $\mathrm{Na}_{2} \mathrm{SO}_{4}$, filtered, and concentrated under reduced pressure. The residue was purified by flash chromatography on silica gel using a gradient of EtOAc (0-40\%) in hexane to afford $0.180 \mathrm{~g}(54 \%)$ of the title compound as a white solid. LC-MS (ESI, $\mathrm{m} / \mathrm{z})$ : $256[\mathrm{M}+\mathrm{H}]^{+} .{ }^{1} \mathrm{H}$ NMR $\left(400 \mathrm{MHz}, \mathrm{DMSO}-d_{6}\right) \delta 11.99(\mathrm{~s}, 1 \mathrm{H}), 8.79(\mathrm{~d}, J=4.6 \mathrm{~Hz}, 2 \mathrm{H}), 8.37$ $(\mathrm{d}, J=7.6 \mathrm{~Hz}, 1 \mathrm{H}), 8.22(\mathrm{~d}, J=4.4 \mathrm{~Hz}, 2 \mathrm{H}), 7.50(\mathrm{t}, J=7.9 \mathrm{~Hz}, 1 \mathrm{H}), 7.15(\mathrm{~d}, J=8.4 \mathrm{~Hz}, 1 \mathrm{H})$, $7.10(\mathrm{~m}, J=7.6 \mathrm{~Hz}, 1 \mathrm{H})$.

\subsubsection{3. tert-Butyl 3-(2-(3-(pyridin-4-yl)-1,2,4-thiadiazol-5-yl)phenoxy)pyrrolidine-1-carboxylate (44)}

To a solution of $43(0.180 \mathrm{~g}, 0.705 \mathrm{mmol}, 1 \mathrm{eq})$ in THF $(5 \mathrm{~mL})$ were added $\mathrm{PPh}_{3}(0.277 \mathrm{~g}$, $1.06 \mathrm{mmol}, 1.5 \mathrm{eq})$ and $40 \%$ DIAD in toluene $(0.520 \mathrm{~mL}, 1.058 \mathrm{mmol}, 1.5 \mathrm{eq})$. The reaction mixture was stirred at room temperature for $10 \mathrm{~min}$. tert-Butyl 3-hydroxypyrrolidine-1carboxylate $(0.158 \mathrm{~g}, 0.846 \mathrm{mmol}, 1.2 \mathrm{eq})$ was added and the reaction mixture was stirred 
at room temperature overnight. The reaction mixture was concentrated under reduced pressure. The residue was purified by flash chromatography on silica gel using a gradient of EtOAc (0-50\%) in hexane to afford $0.105 \mathrm{~g}(35 \%)$ of the title compound as a white solid. LC-MS (ESI, $m / z): 425[\mathrm{M}+\mathrm{H}]^{+} .{ }^{1} \mathrm{H}$ NMR $\left(400 \mathrm{MHz}, \mathrm{DMSO}-d_{6}\right) \delta 8.79(\mathrm{~d}, J=5.7 \mathrm{~Hz}, 2 \mathrm{H})$, $8.49(\mathrm{~d}, J=6.9 \mathrm{~Hz}, 1 \mathrm{H}), 8.20(\mathrm{~d}, J=5.9 \mathrm{~Hz}, 2 \mathrm{H}), 7.67(\mathrm{t}, J=7.0 \mathrm{~Hz}, 1 \mathrm{H}), 7.43(\mathrm{~d}, J=8.4 \mathrm{~Hz}$, $1 \mathrm{H}), 7.27(\mathrm{t}, J=7.6 \mathrm{~Hz}, 1 \mathrm{H}), 5.49(\mathrm{~m}, 1 \mathrm{H}), 3.76(\mathrm{~m}, 1 \mathrm{H}), 3.66(\mathrm{~m}, 1 \mathrm{H}), 3.48(\mathrm{~m}, 2 \mathrm{H}), 2.26$ $(\mathrm{m}, 2 \mathrm{H}), 1.41(\mathrm{~s}, 9 \mathrm{H})$.

3.1.34. 3-(Pyridin-4-yl)-5-(2-(pyrrolidin-3-yloxy)phenyl)-1,2,4-thiadiazole dihydrochloride (45)

To a solution of $44(0.105 \mathrm{~g}, 0.247 \mathrm{mmol}, 1 \mathrm{eq})$ in dioxane $(0.5 \mathrm{~mL})$ cooled at $0{ }^{\circ} \mathrm{C}$ was added $4 \mathrm{~N} \mathrm{HCl}$ in dioxane $(2.0 \mathrm{~mL}, 8.00 \mathrm{mmol}, 32 \mathrm{eq})$. The reaction mixture was stirred at room temperature for $2 \mathrm{~h}$. The reaction mixture was concentrated under reduced pressure. The residue was triturated with $\mathrm{Et}_{2} \mathrm{O}$. The white solid was filtered and dried under high vacuum to afford quantitatively the title compound. LC-MS (ESI, $m / z): 325[\mathrm{M}+\mathrm{H}]^{+}$.

3.1.35. 5-[2-(1-Cyclopentylpyrrolidin-3-yl)oxyphenyl]-3-(4-pyridyl)-1,2,4-thiadiazole (46)

To a solution of $45(0.080 \mathrm{~g}, 0.223 \mathrm{mmol}, 1 \mathrm{eq})$ in $\mathrm{CH}_{2} \mathrm{Cl}_{2}(1 \mathrm{~mL})$ and $\mathrm{MeOH}(1 \mathrm{~mL})$ was added cyclopentanone $(0.049 \mathrm{~mL}, 0.557 \mathrm{mmol}, 2.5 \mathrm{eq})$ and the reaction mixture was stirred at room temperature for $2 \mathrm{~h}$. $\mathrm{NaBH}(\mathrm{OAc})_{3}(0.094 \mathrm{~g}, 0.446 \mathrm{mmol}, 2 \mathrm{eq})$ was added portionwise and the reaction mixture was stirred at room temperature overnight. The reaction mixture was washed with water and the phases were separated. The aqueous phase was extracted with $\mathrm{CH}_{2} \mathrm{Cl}_{2}(3 \times)$. The organic phases were combined, dried over $\mathrm{Na}_{2} \mathrm{SO}_{4}$, filtered, and concentrated under reduced pressure. The residue was purified by reversed-phase HPLC (Xterra C18 column,250 × $19 \mathrm{~mm}, 10 \mu ; 20$ to $60 \%$ ACN in $20 \mathrm{mM}$ ammonium bicarbonate in $20 \mathrm{~min})$ to afford $0.008 \mathrm{~g}(9 \%)$ of the title compound as a white solid. LC-MS (ESI, $m / z): 393[\mathrm{M}+\mathrm{H}]^{+} .{ }^{1} \mathrm{H}$ NMR $\left(400 \mathrm{MHz}, \mathrm{DMSO}-d_{6}\right) \delta 8.80$ $(\mathrm{d}, J=5.9 \mathrm{~Hz}, 2 \mathrm{H}), 8.49(\mathrm{~d}, J=6.9 \mathrm{~Hz}, 1 \mathrm{H}), 8.22(\mathrm{~d}, J=5.9 \mathrm{~Hz}, 2 \mathrm{H}), 7.65(\mathrm{t}, J=7.6 \mathrm{~Hz}, 1 \mathrm{H}), 7.33$ $(\mathrm{d}, J=8.3 \mathrm{~Hz}, 1 \mathrm{H}), 7.25(\mathrm{t}, J=7.1 \mathrm{~Hz}, 1 \mathrm{H}), 5.33(\mathrm{~m}, 1 \mathrm{H}), 2.76-3.12(\mathrm{~m}, 4 \mathrm{H}), 2.30-2.61(\mathrm{~m}, 2 \mathrm{H})$, $2.01(\mathrm{~m} ., 1 \mathrm{H}), 1.78(\mathrm{~m}, 2 \mathrm{H}), 1.65(\mathrm{~m}, 2 \mathrm{H}), 1.37-1.58(\mathrm{~m}, 4 \mathrm{H})$ (Figure S39).

\subsubsection{5-[2-(1-Cyclopentylpyrrolidin-3-yl)oxyphenyl]-3-(4-pyridyl)-1,2,4-thiadiazole (49)}

To a solution 4-acetylpyridine oxime $(0.200 \mathrm{~g}, 1.47 \mathrm{mmol}, 1 \mathrm{eq})$ in THF ( $3 \mathrm{~mL})$ cooled at $-78{ }^{\circ} \mathrm{C}$ was added dropwise $2 \mathrm{M}$ LDA in hexane $(2.2 \mathrm{~mL}, 4.40 \mathrm{mmol}, 3 \mathrm{eq})$ over $30 \mathrm{~min}$. A solution of $19(0.458 \mathrm{~g}, 1.62 \mathrm{mmol}, 1.1 \mathrm{eq})$ in THF $(1 \mathrm{~mL})$ was added dropwise and the reaction mixture was stirred at $-78{ }^{\circ} \mathrm{C}$ for $2 \mathrm{~h}$. The reaction was quenched by the addition of sat. $\mathrm{NH}_{4} \mathrm{Cl}$. After warming to room temperature, the reaction mixture was extracted twice with EtOAc. The organic phases were combined, dried over $\mathrm{Na}_{2} \mathrm{SO}_{4}$, filtered and concentrated under reduced pressure to afford 5-(2-((1-cyclopentylpyrrolidin3-yl)oxy)phenyl)-3-(pyridin-4-yl)-4,5-dihydroisoxazol-5-ol (48) which was dissolved in $\mathrm{MeOH}(3 \mathrm{~mL}) .12 \mathrm{~N} \mathrm{HCl}(3.0 \mathrm{~mL}, 36.0 \mathrm{mmol})$ was added and the reaction mixture was heated at $70{ }^{\circ} \mathrm{C}$ for $3 \mathrm{~h}$. The reaction mixture was concentrated under reduced pressure. The residue was purified by reversed-phase HPLC (Xterra RP18 column,250 × $19 \mathrm{~mm}$, $10 \mu ; 30$ to $90 \% \mathrm{MeOH}$ in $20 \mathrm{mM}$ ammonium bicarbonate in $24 \mathrm{~min}$ ) to afford $0.035 \mathrm{~g}$ $(12 \%)$ of the title compound as a beige solid. LC-MS (ESI, $m / z): 393[\mathrm{M}+\mathrm{H}]^{+} .{ }^{1} \mathrm{H}$ NMR $\left(400 \mathrm{MHz}, \mathrm{DMSO}-\mathrm{d}_{6}\right) \delta 8.77(\mathrm{~d}, J=5.4 \mathrm{~Hz}, 2 \mathrm{H}), 7.93(\mathrm{~d}, J=7.8 \mathrm{~Hz}, 1 \mathrm{H}), 7.85(\mathrm{~d}, J=5.4 \mathrm{~Hz}$, $2 \mathrm{H}), 7.47-7.57(\mathrm{~m}, 2 \mathrm{H}), 7.22(\mathrm{~d}, J=8.3 \mathrm{~Hz}, 1 \mathrm{H}), 7.14(\mathrm{t}, J=7.6 \mathrm{~Hz}, 1 \mathrm{H}), 5.13(\mathrm{~m}, 1 \mathrm{H}), 2.75-2.99$ (m, 3H), 2.47-2.57 (m, 1H), $2.41(\mathrm{~m}, 1 \mathrm{H}), 2.31(\mathrm{~m}, 1 \mathrm{H}), 1.91(\mathrm{~m}, 1 \mathrm{H}), 1.77(\mathrm{~m}, 2 \mathrm{H}), 1.61(\mathrm{~m}$, 2H), 1.34-1.55 (m, 4H) (Figure S40). ${ }^{13} \mathrm{C}$ NMR (150 MHz, DMSO-d 6 ) $\delta 167.09,160.92,154.25$, $150.73,136.04,132.16,127.33,121.04,120.92,115.96,114.42,101.68,77.59,66.08,59.28,51.71$, 31.80, 31.60, 31.51, 23.73 (Figure S41). 


\subsection{Antiviral Assays}

\subsubsection{Cells and Viruses}

The SARS-CoV-2 isolate used was derived from the BetaCov/Belgium/GHB-03021/2020 (EPI ISL407976 | 2020-02-03), which was isolated from a Belgian patient returning from Wuhan in February 2020. The isolate was passaged 7 times on VeroE6 cells which introduced two series of amino acid deletions in the spike protein [29]. The infectious content of the virus stock was determined by titration on Vero E6 cells.

The SARS-CoV-2 variants of concern (VoC) used in this study were Alpha B.1.1.7 (derived from hCoV-19/Belgium/rega-12211513/2020; EPI_ISL_791333, 2020-12-21) 17, and Delta B.1.617.2 (derived from hCoV-19/Belgium/rega-7214/2021; EPI_ISL_2425097; 2021-04-20). The variants were originally isolated in-house from nasopharyngeal swabs taken from travelers returning to Belgium (baseline surveillance) and were subjected to sequencing on a MinION platform (Oxford Nanopore, Oxford, UK) directly from the nasopharyngeal swabs [30]. Virus stocks were then grown on Vero E6 cells in (DMEM 2\% FBS medium) and passaged two times. Median tissue culture infectious doses (TCID50) was defined by end-point titration as previously described [26].

The SARS-CoV-1 strain 200,300,592 (Vietnam) was obtained from the Centers for Disease Control and Prevention (CDC; Atlanta, GA, USA). MERS-CoV-Jordan-N3/2012 (Genbank accession nr KC776174) was obtained from the US Armed Forces Health Surveillance Center, Division of Global Emerging Infections Surveillance and Response System.

VeroE6 cells were maintained in Dulbecco's Modified Eagle's Medium (DMEM; Gibco cat no 41965-039) supplemented with heat-inactivated 10\% $v / v$ fetal calf serum (FCS; Biowest) and $500 \mu \mathrm{g} / \mathrm{mL}$ Geneticin (Gibco cat no 10131-0275) and kept under $5 \% \mathrm{CO}_{2}$ at $37^{\circ} \mathrm{C}$.

\subsubsection{SARS-CoV-1 and SARS-CoV-2 Screening}

The SARS-CoV-1 and SARS-CoV-2 antiviral assay in Vero E6 cells that was used in this study was derived from a previously established SARS-CoV-1 assay [21]. Stock solutions of the various compounds in DMSO $(10 \mathrm{mM})$ were prepared. On day -1 , the test compounds were serially diluted in assay medium and the plates were incubated overnight $\left(37^{\circ} \mathrm{C}\right.$, $5 \% \mathrm{CO}_{2}$, and $95 \%$ relative humidity). After, VeroE6-eGFP cells were plated corresponding to a final density of 25,000 cells per well in black 96-well plates (Greiner Bio-One, Vilvoorde, Belgium; Catalog 655090). On day 0, the cells with compound were infected with SARSCoV-1 (at 20 CCID $_{50}$ per well) or SARS-CoV-2 (at 20 CCID $_{50}$ per well). The plates were incubated in a humidified incubator at $37{ }^{\circ} \mathrm{C}$ and $5 \% \mathrm{CO}_{2}$. At 4 days p.i., the wells were examined for eGFP expression using an argon laser-scanning microscope. The microscope settings were excitation at $488 \mathrm{~nm}$ and emission at $510 \mathrm{~nm}$, and the fluorescence images of the wells were converted into signal values. The antiviral activity was expressed as $\mathrm{EC}_{50}$ defined as the concentration of compound achieving 50\% inhibition of the virus-reduced eGFP signals as compared to the untreated virus-infected control cells.

The same methodology was applied for the $\mathrm{VoC}$, in which cells were infected with the SARS-CoV-2 at a final MOI of approximately 0.05 TCID50/cell. The final dilution of the different strains was adapted in order to obtain a similar MOI between all variants of interest.

The cytotoxicity of the compounds for VeroE6 cells in the absence of virus was evaluated in a standard MTS assay as previously described [31].

MERS-CoV cytopathic effect reduction assays were performed in Huh-7 cells $(1.5 \times 104$ cells /well $)$ using 96-well plates. Cells, seeded on the day prior to infection, were incubated with $100 \mu \mathrm{L}$ volumes of 2 -fold serial dilutions of compounds in infection medium, followed by infection with 225 PFU of MERS-CoV in $50 \mu \mathrm{L}$, yielding a total assay volume of $150 \mu \mathrm{L}$. Non-infected cells were treated in parallel with the same dilution series of compounds to determine cytotoxicity. After incubation for $42 \mathrm{~h}$ at $37^{\circ} \mathrm{C}$, cell viability was quantified with the CellTiter-96 Aqueous Non-radioactive Cell Proliferation Kit (Promega, Madison, WI, USA) and absorption at $495 \mathrm{~nm}$ was measured with an EnVision multilabel plate reader (PerkinElmer) and after normalization to uninfected (and untreated cells), 
EC50 and CC50 values were determined by nonlinear regression using GraphPad Prism v8.0 (San Diego, CA, USA).

All SARS-CoV-1- and SARS-CoV-2-related work was conducted in the high-containment BSL3+ facilities of the KU Leuven Rega Institute (3CAPS) under licenses AMV 30112018 SBB 21920180892 and AMV 23102017 SBB 21920170589 according to institutional guidelines. Experiments with infectious MERS-CoV and SARS-CoV-1 were performed at the LUMC biosafety level 3 (BSL-3) facilities.

\subsection{Pseudotyped Virus Neutralization Assay}

Production of VSV pseudotyped with MERS-CoV spike [32] and SARS-CoV-2 spike [33] was previously described. Briefly, HEK-293T cells were transfected with pCAGGS expression vectors encoding MERS-CoV spike or SARS-CoV-2 spike carrying a 16 or 18 a.a. cytoplasmic tail truncation, respectively. On day one post transfection, cells were infected with the VSV-G pseudotyped VSV $\Delta$ G bearing the firefly (Photinus pyralis) luciferase reporter gene. Twenty-four hours later, supernatants containing MERS-CoV spike, SARS-CoV spike, or SARS-CoV-2 spike pseudotyped VSV particles were harvested and titrated on African green monkey kidney Vero E6 (ATCC\#CRL-1586) cells.

In the virus neutralization assay, compounds were threefold serially diluted at two times the desired final concentration in DMEM supplemented with $1 \%$ fetal bovine serum, $100 \mathrm{U} / \mathrm{mL}$ Penicillin, and $100 \mu \mathrm{g} / \mathrm{mL}$ Streptomycin (Lonza, Basel, Switzerland). Monoclonal antibodies against MERS-CoV spike (7.7G6) [32] or SARS2-CoV-2 spike (REGN10933) [34] were included as a positive control. Diluted compounds and $\mathrm{mAbs}$ were incubated with an equal volume of pseudotyped VSV particles for $1 \mathrm{~h}$ at room temperature, inoculated on confluent VeroE6 monolayers in a 96-well plate, and further incubated at $37^{\circ} \mathrm{C}$ for $24 \mathrm{~h}$. Cells were lysed with Luciferase Cell Culture Lysis $5 \times$ Reagent (Promega, Madison, Wisconsin, USA) at room temperature for $30 \mathrm{~min}$. Luciferase activity was measured on a Promega GloMax ${ }^{\circledR}$ Explorer luminometer using D-luciferin as a substrate (Promega, Madison, Wisconsin, USA). The half-maximal inhibitory concentrations $\left(\mathrm{IC}_{50}\right)$ were determined using 4-parameter logistic regression (GraphPad Prism version 8, San Diego, CA, USA).

\subsection{Nsp14 RapidFire MS Screening Assay}

An endpoint 384-well plate assay was developed to assess nsp14 activity [35]. Briefly, enzyme and substrates, SAM ( $S$-(5'-adenosyl)-l-methionine chloride hydrochloride [Cayman Chemical, Ann Arbor, MI, USA] and cap G(5')ppp $\left(5^{\prime}\right) \mathrm{G}$ sodium salt [New England Biolabs, Ipswich, MA, USA]) were incubated to allow the reaction to take place, and then the product was quantified using MS. Assays were performed in 384-well, clear, flat-bottom plates (Greiner 781101) to a final volume of $20 \mu \mathrm{L}$. Components were diluted in buffer (20 mM Tris, pH 8.0, $50 \mathrm{mM} \mathrm{NaCl}$ ) containing $1 \mathrm{mM}$ TCEP (Thermo Scientific, Waltham, MA, USA), $0.1 \mathrm{mg} / \mathrm{mL}$ bovine serum albumin, $0.005 \%$ Nonidet $\mathrm{P} 40$ (Roche), and $3 \mathrm{mM} \mathrm{MgCl} 2$. In the assay, $5 \mathrm{nM}$ nsp14 was incubated with $1 \mu \mathrm{M}$ SAM and $0.7 \mu \mathrm{M}$ cap (FAC). Following a 60 min incubation, the reaction was quenched using 1\% formic acid (VWR, Radnor, PA, USA) containing $0.03 \mu \mathrm{g} / \mathrm{mL} S$-adenosylhomocysteine- $\mathrm{d} 4$ (d4SAH; Cambridge Bioscience, Cambridge, UK) and loaded on the RapidFire system by aspiration for $600 \mathrm{~ms}$ using the Agilent RapidFire 365 high-throughput system with integrated solid-phase extraction (SPE) interfaced with the Agilent 6740 triple quadrupole mass spectrometer. The sample was then automatically loaded onto a C18 Type C SPE cartridge (Agilent Technologies), and buffer salts and protein matrix were removed from the sample by washing the cartridge with the load solution (water containing $0.1 \%$ trifluoroacetic acid [TFA]) at a flow rate of $1.5 \mathrm{~mL} / \mathrm{min}$ for $5000 \mathrm{~ms}$. The retained and purified analytes were eluted from the cartridge with the elution solution (acetonitrile: water [9:1, v/v] containing $0.1 \%$ TFA) at $1.25 \mathrm{~mL} / \mathrm{min}$ for $5000 \mathrm{~ms}$ and directed to the mass spectrometer. The cartridge was re-equilibrated with load solution at $1.5 \mathrm{~mL} / \mathrm{min}$ for $500 \mathrm{~ms}$. Both $S$-adenosylhomocysteine (SAH) and d4SAH were assessed using multiple selected reaction monitoring (MRM) transitions of 385.1/134 for SAH and 389.2/135.9 for d4SAH. The dwell time was $50 \mathrm{~ms}$ for each transition. The 
fragmentor voltage was set to $120 \mathrm{~V}$ for $\mathrm{SAH}$ and 100 for $\mathrm{d} 4 \mathrm{SAH}$, the collision energy to $12 \mathrm{~V}$ for SAH and $14 \mathrm{~V}$ for d4SAH, the cell accelerator voltage to $5 \mathrm{~V}$, and the delta electron multiplier voltage to $200 \mathrm{~V}$. The mass spectrometer was operated with a gas temperature of $350{ }^{\circ} \mathrm{C}$, gas flow rate of $7 \mathrm{~L} / \mathrm{min}$, nebulizer pressure of $40 \mathrm{psi}$, and capillary voltage of $3000 \mathrm{~V}$. The areas under the daughter ion peaks of SAH and d4SAH were integrated using RapidFire QQQ Quantitative Analysis software (Agilent Technologies), and the area ratios of the SAH to the internal standard d4SAH were used for quantitation.

\subsection{SARS-CoV-2 Polymerase Assay}

The compound concentrations leading to $50 \%$ inhibition of polymerase-mediated RNA synthesis was determined in IC 50 buffer (50 mM HEPES pH 8.0, $10 \mathrm{mM} \mathrm{KCl}, 2 \mathrm{mM}$ $\mathrm{MnCl}_{2}, 2 \mathrm{mM} \mathrm{MgCl}, 10 \mathrm{mM}$ DTT) containing $350 \mathrm{nM}$ of Poly(A) template, seven various concentrations of compound (from 1 to $100 \mu \mathrm{M}$ ) and $150 \mathrm{nM}$ of nsp2 in complex with $450 \mathrm{nM}$ of nsp7L8 and $450 \mathrm{nM}$ of nsp8.

Reactions were conducted in $40 \mu \mathrm{L}$ volume on a 96-well Nunc plate. All experiments were robotized by using a BioMek 4000 automate (Beckman). Two microliters of each compound diluted in $100 \%$ DMSO was added in wells to the chosen concentration (5\% DMSO final concentration). For each assay, the enzyme mix was distributed in wells after a $5 \mathrm{~min}$ incubation at room temperature to form the active complex. Reactions were started by the addition of the UTP mix and were incubated at $30^{\circ} \mathrm{C}$ for $20 \mathrm{~min}$. Reaction assays were stopped by the addition of $20 \mu \mathrm{L}$ EDTA $100 \mathrm{mM}$. Positive and negative controls consisted, respectively, of a reaction mix with 5\% DMSO final concentration or EDTA $100 \mathrm{mM}$ instead of compounds. Reaction mixes were then transferred to Greiner plate using a Biomek I5 automate (Beckman). Picogreen ${ }^{\circledR}$ fluorescent reagent was diluted to $1 / 800^{\circ}$ in TE buffer according to the manufacturer and $60 \mu \mathrm{L}$ of reagent was distributed into each well of the Greiner plate. The plate was incubated for $5 \mathrm{~min}$ in the dark at room temperature and the fluorescence signal was then read at $480 \mathrm{~nm}$ (excitation) and $530 \mathrm{~nm}$ (emission) using a TecanSafire2.

$\mathrm{IC}_{50}$ was determined using the equation: $\%$ of active enzyme $=100 /\left(1+(\mathrm{I}) 2 / \mathrm{IC}_{50}\right)$, where I is the concentration of inhibitor and $100 \%$ of activity is the fluorescence intensity without inhibitor. $\mathrm{IC}_{50}$ was determined from curve fitting using Prism software. For each value, results were obtained using triplicate in a single experiment. $3^{\prime}$ dUTP was used as an inhibitor control.

\subsection{Furin and TMPRSS2 Enzymatic Assays}

Recombinant furin was purchased from BioLegend (\#719406), human recombinant TRMPSS2 from Cliniscience (ref LS-G57269-100), and the fluorogenic DABSYL/GluTNSPRRAR $\downarrow S V A S-E D A N S-l a b e l e d$ peptides encompassing the S1/S2 cleavage site were purchased from Genscript. Briefly, the reactions were performed at room temperature in black 384-well 553 polystyrene low-volume plates (CELLSTAR-Greiner Bio-One \# 784476) at a final volume of $15 \mu \mathrm{L}$. The fluorescent peptides were used at $5 \mu \mathrm{M}$ and the reactions were performed in $50 \mathrm{mM}$ Tris buffer ( $\mathrm{pH} 7.5), 0.2 \%$ Triton X-100, $1 \mathrm{mM} \mathrm{CaCl}_{2}$ in the presence of $2 \mathrm{nM}$ of furin. The inhibitors solubilized in DMSO were tested at $50 \mu \mathrm{M}$ with $5 \%$ DMSO final concentration in the enzymatic assay.

For the TMPRSS2 assay, the fluorescent peptides were used at $5 \mu \mathrm{M}$ and the reactions were performed in $50 \mathrm{mM}$ Tris buffer (pH 8), and $150 \mathrm{mM} \mathrm{NaCl}$ and TMPRSS2 were added at final concentrations of $50 \mathrm{nM}$.

The cleavage of the synthetic peptides was quantitated by determining the increase in EDANS (562 nM) fluorescence following the release of the DABCYL quencher. The EDANS was excited at $335 \mathrm{nM}$ using a Safire 2 Tecan fluorimeter. Each reaction was performed in triplicate. 


\subsection{SARS-CoV-2 Main Protease (Mpro) Assay}

SARS-CoV-2 main protease (Mpro) was recombinantly produced as described before [36]. Compounds were tested in a Förster resonance energy transfer (FRET) assay for inhibition of the SARS-CoV-2 Mpro. The peptide Dabcyl-KTSAVLQ $\downarrow S G F R K M-E(E d a n s)-$ NH2 (Biosyntan, Berlin, Germany) ( $\downarrow$ indicates the cleavage site), corresponding to the P7-P6' residues of the nsp4-nsp5 processing site of the viral polyprotein pp1a/pp1ab, was used as the substrate. Quenching of the Edans fluorescence by the Dabcyl residue was eliminated after cleavage of the scissile bond between P1-Gln and P1'-Ser and the difference in fluorescence emission was measured with a Tecan Spark fluorescence plate reader, operated at an excitation wavelength of $360 \mathrm{~nm}$ and an emission wavelength of $460 \mathrm{~nm}$.

Candidate compounds were kept in a DMSO stock solution; the Mpro was in a buffer containing $20 \mathrm{mM}$ HEPES, $120 \mathrm{mM} \mathrm{NaCl}, 0.4 \mathrm{mM}$ EDTA, 20\% glycerol, pH 7.0. DTT $(4 \mathrm{mM})$ was added to the buffer prior to running the assay. Following incubation of $50 \mathrm{nM}$ SARS-CoV-2 Mpro with $100 \mu \mathrm{M}$ of the candidate compound for $10 \mathrm{~min}$ at $37^{\circ} \mathrm{C}$, the reaction was initiated by the addition of $10 \mu \mathrm{M}$ of the FRET substrate to each well. The final DMSO concentration was $<2 \%$.

\section{Conclusions}

A high-throughput screening of a drug-like compound library led to the discovery of a hit compound 1, showing low micromolar activity against SARS-CoV-2 with a selectivity index of 5. Exploration of the SAR yielded compounds that were equally active, but showed a decreased cytotoxicity and hence displayed an improved SI. Hit compound 1 was profiled more extensively and was shown to be active against the VoCs of SARS-CoV-2, as well as against various betacoronaviruses. Furthermore, pseudovirus neutralization assays revealed that the compound exerts its antiviral effect via interference with viral entry. Overall, this study highlights the possibility to discover new hit compounds with promising activities against SARS-CoV-2 from a phenotypic approach. More investigations are, however, needed to improve the antiviral potency and to study its mechanism of action.

Supplementary Materials: The following are available online, Figure S1: ${ }^{1} \mathrm{H}$ NMR of compound 1 in DMSO- $d_{6}$. Figure S2: ${ }^{13} \mathrm{C}$ NMR of compound 1 in DMSO- $d_{6}$. Figure S3: ${ }^{1} \mathrm{H}$ NMR of compound 1a in DMSO- $d_{6}$. Figure S4: ${ }^{13} \mathrm{C}$ NMR of compound $\mathbf{1 a}$ in DMSO- $d_{6}$. Figure S5: ${ }^{1} \mathrm{H}$ NMR of compound $\mathbf{1 b}$ in DMSO- $d_{6}$. Figure S6: ${ }^{1} \mathrm{H}$ NMR of compound 8 in DMSO- $d_{6}$. Figure S7: ${ }^{1} \mathrm{H}$ NMR of compound 9 in $\mathrm{CD}_{3} \mathrm{OD}$. Figure S8: ${ }^{13} \mathrm{C}$ NMR of compound 9 in DMSO- $d_{6}$. Figure S9: ${ }^{1} \mathrm{H}$ NMR of compound 10 in $\mathrm{CD}_{3} \mathrm{OD}$. Figure S10: ${ }^{13} \mathrm{C}$ NMR of compound 10 in DMSO- $d_{6}$. Figure S11: ${ }^{1} \mathrm{H}$ NMR of compound 11 in $\mathrm{CD}_{3} \mathrm{OD}$. Figure S12: ${ }^{13} \mathrm{C}$ NMR of compound 11 in DMSO- $d_{6}$. Figure S13: ${ }^{1} \mathrm{H}$ NMR of compound 12 in $\mathrm{CD}_{3} \mathrm{OD}$. Figure S14: ${ }^{13} \mathrm{C}$ NMR of compound 12 in DMSO- $d_{6}$. Figure S15: ${ }^{1} \mathrm{H}$ NMR of compound 13 in DMSO- $d_{6}$. Figure S16: ${ }^{13} \mathrm{C}$ NMR of compound 13 in DMSO- $d_{6}$. Figure S17: ${ }^{1} \mathrm{H}$ NMR of compound 14 in DMSO- $d_{6}$. Figure S18: ${ }^{13} \mathrm{C}$ NMR spectrum of compound 14 in DMSO- $d_{6}$. Figure S19: ${ }^{1} \mathrm{H}$ NMR spectrum of compound 23 in DMSO- $d_{6}$. Figure S20: ${ }^{1} \mathrm{H}$ NMR of compound 24 in $\mathrm{CD}_{3} \mathrm{OD}$. Figure S21: ${ }^{13} \mathrm{C}$ NMR of compound 24 in DMSO- $d_{6}$. Figure S22: ${ }^{1} \mathrm{H}$ NMR of compound 25 in DMSO- $d_{6}$. Figure S23: ${ }^{13} \mathrm{C}$ NMR spectrum of compound 25 in DMSO- $d_{6}$. Figure S24: ${ }^{1} \mathrm{H}$ NMR spectrum of compound 26 in DMSO- $d_{6}$. Figure S25: ${ }^{13} \mathrm{C}$ NMR of compound 26 in DMSO- $d_{6}$. Figure S26: ${ }^{1} \mathrm{H}$ NMR of compound 27 in DMSO- $d_{6}$. Figure S27: ${ }^{1} \mathrm{H}$ NMR of compound 28 in DMSO- $d_{6}$. Figure S28: ${ }^{13} \mathrm{C}$ NMR of compound 28 in DMSO- $d_{6}$. Figure S29: ${ }^{1} \mathrm{H}$ NMR of compound 29 in DMSO- $d_{6}$. Figure S30: ${ }^{13} \mathrm{C}$ NMR of compound 29 in DMSO- $d_{6}$. Figure S31: ${ }^{1} \mathrm{H}$ NMR of compound 30 in DMSO- $d_{6}$. Figure S32: ${ }^{13} \mathrm{C}$ NMR of compound 30 in DMSO- $d_{6}$. Figure S33: ${ }^{1} \mathrm{H}$ NMR of compound 31 in DMSO- $d_{6}$. Figure S34: ${ }^{13} \mathrm{C}$ NMR of compound 31 in DMSO- $d_{6}$. Figure S35: ${ }^{1} \mathrm{H}$ NMR of compound 35 in DMSO$d_{6}$. Figure S36: ${ }^{13} \mathrm{C}$ NMR of compound 35 in DMSO- $d_{6}$. Figure S37: ${ }^{1} \mathrm{H}$ NMR of compound 38 in DMSO- $d_{6}$. Figure S38: ${ }^{13} \mathrm{C}$ NMR of compound 38 in DMSO- $d_{6}$. Figure S39: ${ }^{1} \mathrm{H}$ NMR of compound 46 in DMSO- $d_{6}$. Figure S40: ${ }^{1} \mathrm{H}$ NMR of compound 49 in DMSO- $d_{6}$. Figure S41: ${ }^{13} \mathrm{C}$ NMR of compound 49 in DMSO- $d_{6}$.

Author Contributions: Conceptualization, D.B., P.C., P.L., D.J., J.N. and A.M.; methodology, D.B., L.V., D.J., P.C., J.N., S.D.J. and A.M.; validation, D.B., L.V., D.J., R.H., C.R., E.D., B.C., E.J.S., M.J.v.H., F.v.K., P.C., J.N., S.D.J. and A.M.; formal analysis, D.B., L.V., H.K., P.L. and D.J.; investigation, M.K., 
P.A., M.Z., H.L., P.W., S.A., L.Z., X.S., A.D., C.E., J.-C.G. and E.L.; resources, E.L., R.H., C.R., E.D., B.C., E.J.S., M.J.v.H., F.v.K., P.C. and J.N.; data curation, L.V., D.J., R.H., C.R., E.D., B.C., E.J.S., M.J.v.H. and F.v.K.; writing—original draft preparation, D.B. and S.D.J.; writing-review and editing, D.B., L.V., D.J., R.H., C.R., E.D., B.C., E.J.S., M.J.v.H., F.v.K., P.C., J.N., S.D.J. and A.M.; supervision, D.B., J.N. and A.M.; project administration, K.C.; funding acquisition, P.L., P.C. and J.N. All authors have read and agreed to the published version of the manuscript.

Funding: Part of this research work was performed using the 'Caps-It' research infrastructure (project ZW13-02) that was financially supported by the Hercules Foundation and Rega Foundation, KU Leuven'. This project has received funding from the European Union's Horizon 2020 research and Innovation program under grant No 10100362 (the SCORE project). Part of this work was performed under the CARE project. The CARE project has received funding from the Innovative Medicines Initiative 2 Joint Undertaking (JU) under grant agreement No 101005077. The JU receives support from the European Union's Horizon 2020 research and innovation programme and EFPIA and Bill \& Melinda Gates Foundation, Global Health Drug Discovery Institute, University of Dundee. The content of this publication only reflects the author's view and the JU is not responsible for any use that may be made of the information it contains.

Institutional Review Board Statement: Not applicable.

Informed Consent Statement: Not applicable.

Data Availability Statement: Not applicable.

Acknowledgments: We want to thank TCG Life Sciences for their assistance in the synthesis of some of the compounds reported in this article.

Conflicts of Interest: The authors declare no conflict of interest.

Sample Availability: Samples of the compounds are not available from the authors.

\section{References}

1. Zhu, N.; Zhang, D.; Wang, W.; Li, X.; Yang, B.; Song, J.; Zhao, X.; Huang, B.; Shi, W.; Lu, R.; et al. China Novel Coronavirus Investigating and Research Team. A novel coronavirus from patients with pneumonia in China, 2019. N. Engl. J. Med. 2020, 382, 727-733. [CrossRef] [PubMed]

2. Wang, C.; Horby, P.W.; Hayden, F.G.; Gao, G.F. A novel coronavirus outbreak of global health concern. Lancet 2020, 395, 15-18. [CrossRef]

3. Johns Hopkins University of Medicine-Coronavirus Resource Center. Available online: https://coronavirus.jhu.edu/map.html (accessed on 8 December 2021).

4. Prüß, B.M. Current State of the First COVID-19 Vaccines. Vaccines 2021, 9, 30. [CrossRef] [PubMed]

5. Riva, L.; Yuan, S.; Yin, X.; Martin-Sancho, L.; Matsunaga, N.; Pache, L.; Burgstaller-Muehlbacher, S.; De Jesus, P.D.; Teriete, P.; Hull, M.V.; et al. Discovery of SARS-CoV-2 antiviral drugs through large-scale compound repurposing. Nature 2020, 586, 113-119. [CrossRef] [PubMed]

6. Dittmar, M.; Lee, J.S.; Whig, K.; Segrist, E.; Li, M.; Kamalia, B.; Castellana, L.; Ayyanathan, K.; Cardenas-Diaz, F.L.; Morrisey, E.E.; et al. Drug repurposing screens reveal cell-type-specific entry pathways and FDA-approved drugs active against SARS-Cov-2. Cell Rep. 2021, 35, 108959. [CrossRef]

7. Yuan, S.; Chan, J.F.W.; Chik, K.K.H.; Chan, C.C.Y.; Tsang, J.O.L.; Liang, R.; Cao, J.; Tang, K.; Chen, L.; Wen, K.; et al. Discovery of the FDA-approved drugs bexarotene, cetilistat, diiodohydroxyquinoline, and abiraterone as potential COVID-19 treatments with a robust two-tier screening system. Pharmacol. Res. 2020, 159, 104960. [CrossRef]

8. Mirabelli, C.; Wotring, J.W.; Zhang, C.J.; McCarty, S.M.; Fursmidt, R.; Pretto, C.D.; Qiao, Y.; Zhang, Y.; Frum, T.; Kadambi, N.S.; et al. Morphological cell profiling of SARS-CoV-2 infection identifies drug repurposing candidates for COVID-19. Proc. Natl. Acad. Sci. USA 2021, 118, e2105815118. [CrossRef] [PubMed]

9. V'kovski, P.; Kratzel, A.; Steiner, S.; Stalder, H.; Thiel, V. Coronavirus biology and replication:implications for SARS-CoV-2. Nat. Rev. Microbiol. 2021, 19, 155-170. [CrossRef]

10. Ogando, N.S.; El Kazzi, P.; Zevenhoven-Dobbe, J.C.; Bontes, B.W.; Decombe, A.; Posthuma, C.C.; Thiel, V.; Canard, B.; Ferron, F.; Decroly, E.; et al. Structure-function analysis of the nsp14 N7-guanine methyltransferase reveals an essential role in Betacoronavirus replication. Proc. Natl. Acad. Sci. USA 2021, 18, e2108709118. [CrossRef]

11. Canal, B.; Fujisawa, R.; McClure, A.W.; Deegan, T.D.; Wu, M.; Ulferts, R.; Weissmann, F.; Drury, L.S.; Bertolin, A.P.; Zeng, J.; et al. Identifying SARS-CoV-2 antiviral compounds by screening for small molecule inhibitors of nsp15 endoribonuclease. Biochem. J. 2021, 478, 2465-2479. [CrossRef] [PubMed]

12. Amin, S.A.; Banerjee, S.; Ghosh, K.; Gayen, S.; Jha, T. Protease targeted COVID-19 drug discovery and its challenges: Insight into viral main protease (Mpro) and papain-like protease (PLpro) inhibitors. Bioorg. Med. Chem. 2021, 29, 115860. [CrossRef] [PubMed] 
13. Vandyck, K.; Deval, J. Considerations for the discovery and development of 3-chymotrypsin-like cysteine protease inhibitors targeting SARS-CoV-2 infection. Curr. Opin. Virol. 2021, 49, 36-40. [CrossRef] [PubMed]

14. Peng, Q.; Peng, R.; Yuan, B.; Zhao, J.; Wang, M.; Wang, X.; Wang, Q.; Sun, Y.; Fan, Z.; Qi, J.; et al. Structural and Biochemical Characterization of the nsp12-nsp7-nsp8 Core Polymerase Complex from SARS-CoV-2. Cell Rep. 2020, 31, 107774. [CrossRef] [PubMed]

15. Chien, M.; Anderson, T.K.; Jockusch, S.; Tao, C.; Li, X.; Kumar, S.; Russo, J.J.; Kirchdoerfer, R.N.; Ju, J. Nucleotide analogues as inhibitors of SARS-CoV-2 polymerase, a Key drug target for COVID-19. J. Proteome Res. 2020, 19, 4690-4697. [CrossRef] [PubMed]

16. Boras, B.; Jones, R.M.; Anson, B.J.; Arenson, D.; Aschenbrenner, L.; Bakowski, M.A.; Beutler, N.; Binder, J.; Chen, E.; Eng, H.; et al. Preclinical characterization of an intravenous coronavirus 3CL protease inhibitor for the potential treatment of COVID19. Nat. Commun. 2021, 12, 6055. [CrossRef]

17. Owen, D.R.; Allerton, C.M.N.; Anderson, A.S.; Aschenbrenner, L.; Avery, M.; Berritt, S.; Boras, B.; Cardin, R.D.; Carlo, A.; Coffman, K.J.; et al. An oral SARS-CoV-2 Mpro inhibitor clinical candidate for the treatment of COVID-19. Science 2021, 374, 1586-1593. [CrossRef]

18. De Clercq, E. Remdesivir: Quo vadis? Biochem. Pharmacol. 2021, 193, 114800. [CrossRef]

19. Painter, G.R.; Natchus, M.G.; Cohen, O.; Holman, W.; Painter, W.P. Developing a direct acting, orally available antiviral agent in a pandemic: The evolution of molnupiravir as a potential treatment for COVID-19. Curr. Opin. Virol. 2021, 50, 17-22. [CrossRef]

20. Moffat, J.G.; Vincent, F.; Lee, J.A.; Eder, J.; Prunotto, M. Opportunities and challenges in phenotypic drug discovery: An industry perspective. Nat. Rev. Drug Discov. 2017, 16, 531-543. [CrossRef]

21. Ivens, T.; Van den Eynde, C.; Van Acker, K.; Nijs, E.; Dams, G.; Bettens, E.; Ohagen, A.; Pauwels, R.; Hertogs, K. Development of a homogeneous screening assay for automated detection of antiviral agents active against severe acute respiratory syndromeassociated coronavirus. J. Virol. Methods 2005, 129, 56-63. [CrossRef]

22. Sondhi, S.M.; Kumar, S.; Kumar, N.; Roy, P. Synthesis anti-inflammatory and anticancer activity evaluation of some pyrazole and oxadiazole derivatives. Med. Chem. Res. 2012, 21, 3043-3052. [CrossRef]

23. Tsunoda, T.; Yamamiya, Y.; Itô, S. 1,1'-(azodicarbonyl)dipiperidine-tributylphosphine, a new reagent system for mitsunobu reaction. Tetrahedron Lett. 1993, 34, 1639-1642. [CrossRef]

24. Basavaprabhu, V.T.M.; Panguluri, N.R.; Sureshbabu, V.V. Propanephosphonic acid anhydride (T3P). A benign reagent for diverse applications inclusive of large-scale synthesis. Synthesis 2013, 45, 1569-1601. [CrossRef]

25. Wehn, P.M.; Harrington, P.E.; Eksterowicz, J.F. Facile synthesis of substituted 5-amino- and 3-amino-1,2,4-thiadiazoles from a common precursor. Org. Lett. 2009, 11, 5666-5669. [CrossRef] [PubMed]

26. Li, Y.; Cao, L.; Li, G.; Cong, F.; Li, Y.; Sun, J.; Luo, Y.; Chen, G.; Li, G.; Wang, P.; et al. Remdesivir metabolite GS-441524 effectively inhibits SARS-CoV-2 infection in mouse models. J. Med. Chem. 2021. online ahead of print. [CrossRef]

27. Delang, L.; Li, C.; Tas, A.; Querat, G.; Albulescu, I.C.; De Burghgraeve, T.; Segura Guerrero, N.A.; Gigante, A.; Piorkowski, G.; Decroly, E.; et al. The viral capping enzyme nsP1: A novel target for the inhibition of chikungunya virus infection. Sci. Rep. 2016, 6, 31819. [CrossRef]

28. Fish, P.V.; Allan, G.A.; Bailey, S.; Blagg, J.; Butt, R.; Collis, M.G.; Greiling, D.; James, K.; Kendall, J.; McElroy, A.; et al. Potent and selective nonpeptidic inhibitors of procollagen C-proteinase. J. Med. Chem. 2007, 50, 3442-3456. [CrossRef]

29. Boudewijns, R.; Thibaut, H.J.; Kaptein, S.J.F.; Li, R.; Vergote, V.; Seldeslachts, L.; Van Weyenbergh, J.; De Keyzer, C.; Bervoets, L.; Sharma, S.; et al. STAT2 signaling restricts viral dissemination but drives severe pneumonia in SARS-CoV-2 infected hamsters. Nat. Commun. 2020, 11, 5838. [CrossRef]

30. Abdelnabi, R.; Boudewijns, R.; Foo, C.S.; Seldeslachts, L.; Sanchez-Felipe, L.; Zhang, X.; Delang, L.; Maes, M.; Kaptein, S.J.F.; Weynand, B.; et al. Comparing infectivity and virulence of emerging SARS-CoV-2 variants in Syrian hamsters. EBioMedicine 2021, 68, 103403. [CrossRef]

31. Jochmans, D.; Leyssen, P.; Neyts, J. A novel method for high-throughput screening to quantify antiviral activity against viruses that induce limited CPE. J. Virol. Methods 2012, 183, 176-179. [CrossRef]

32. Widjaja, I.; Wang, C.; van Haperen, R.; Gutiérrez-Álvarez, J.; van Dieren, B.; Okba, N.M.A.; Stalin Raj, V.; Li, W.; Fernandez-Delgado, R.; Grosveld, F.; et al. Towards a solution to MERS: Protective human monoclonal antibodies targeting different domains and functions of the MERS-coronavirus spike glycoprotein. Emerg. Microbes Infect. 2019, 8, 516-530. [CrossRef] [PubMed]

33. Wang, C.; Li, W.; Drabek, D.; Okba, N.M.A.; van Haperen, R.; Osterhaus, A.D.M.E.; van Kuppeveld, F.J.M.; Haagmans, B.L.; Grosveld, F.; Bosch, B.J. A human monoclonal antibody blocking SARS-CoV-2 infection. Nat. Commun. 2020, 11, 2251. [CrossRef] [PubMed]

34. Hansen, J.; Baum, A.; Pascal, K.E.; Russo, V.; Giordano, S.; Wloga, E.; Fulton, B.O.; Yan, Y.; Koon, K.; Patel, K.; et al. Studies in humanized mice and convalescent humans yield a SARS-CoV-2 antibody cocktail. Science 2020, 369, 1010-1014. [CrossRef] [PubMed]

35. Pearson, L.A.; Green, C.J.; De Lin, P.A.P.; Gray, D.W.; Cowling, V.H.; Fordyce, E.A.F. Development of a high-throughput screening assay to identify inhibitors of the SARS-CoV-2 guanine-N7-methyltransferase using rapidFire mass spectrometry. SLAS Discov. 2021, 26, 749-756. [CrossRef]

36. Zhang, L.; Lin, D.; Sun, X.; Curth, U.; Drosten, C.; Sauerhering, L.; Becker, S.; Rox, K.; Hilgenfeld, R. Crystal structure of SARS-CoV-2 main protease provides a basis for design of improved $\alpha$-ketoamide inhibitors. Science 2020, 368, 409-412. [CrossRef] 